\title{
Collagen I fibrous substrates modulate the proliferation and secretome of estrogen receptor-positive breast tumor cells in a hormone-restricted microenvironment
}

Ana M. Reyes-Ramos ${ }^{a}$, Yasmín R. Álvarez-García ${ }^{b}$, Natalia Solodin ${ }^{c}$, Jorge Almodovard, Elaine T. Alarid ${ }^{\mathrm{c}}$, Wandaliz Torres-Garcia ${ }^{\mathrm{e}}$ and Maribella Domenech ${ }^{\mathrm{a}^{*}}$

a Department of Chemical Engineering, University of Puerto Rico-Mayagüez, Call Box 9000, Mayagüez, Puerto Rico 00681-9000, USA

${ }^{b}$ Department of Chemistry, University of Wisconsin-Madison, Madison, WI 53706 USA

${ }^{c}$ Department of Oncology, McArdle Laboratories for Cancer Research and University of Wisconsin Carbone Comprehensive Cancer Center, University of Wisconsin-Madison, 1111 Highland Avenue, Madison, WI 53705, USA

${ }^{d}$ Ralph E. Martin Department of Chemical Engineering, University of Arkansas, 3202 Bell Engineering Center, Fayetteville, AR 72701, USA

${ }^{e}$ Department of Industrial Engineering, University of Puerto Rico - Mayagüez, Call Box 9000, Mayagüez, Puerto Rico 00681-9000, USA

*Corresponding author.maribella.domenech@upr.edu

Pages: 24

Figures: 5

Tables:1 


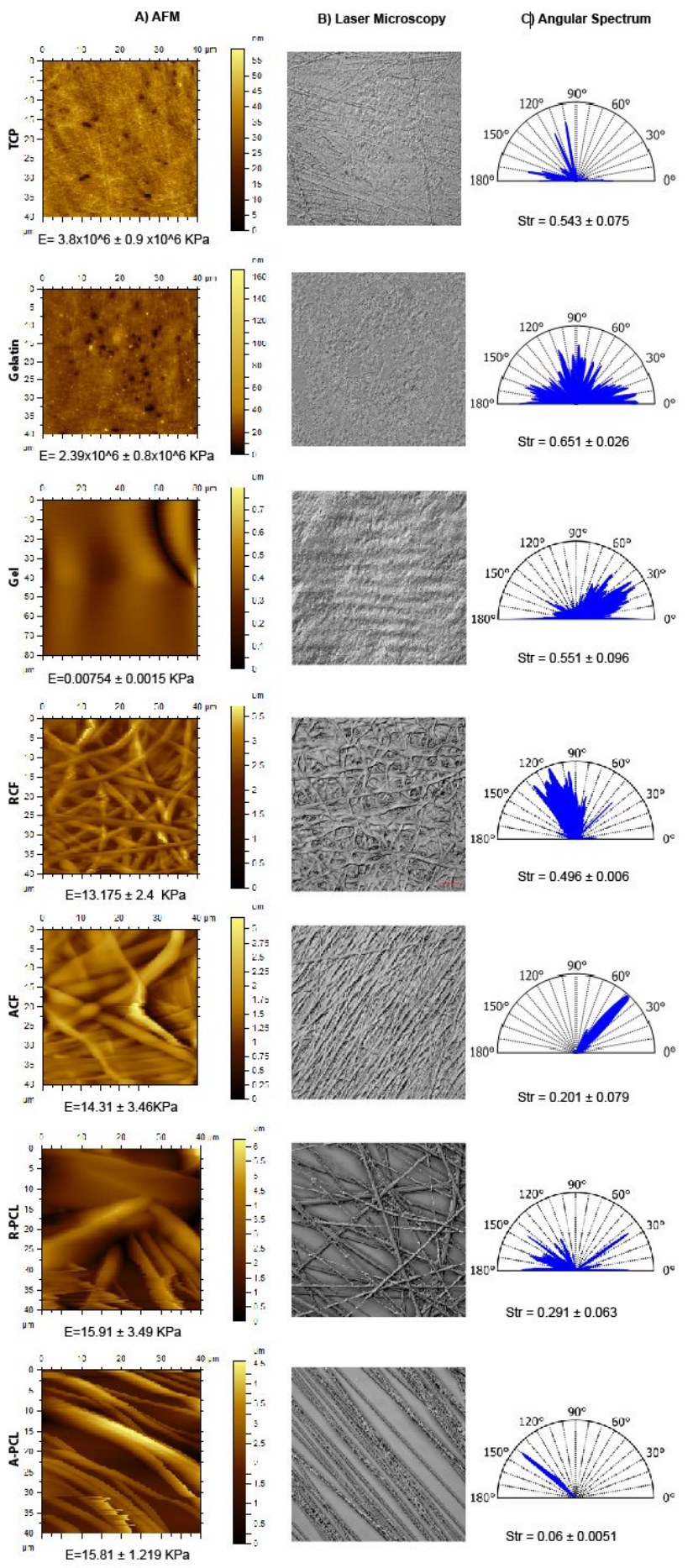

Figure S1-Sn. Representative images of the fiber organization on the substrate surface. A) AFM technique to obtain young's modulus of all the substrates. B) Surface orientation through a 3D laser confocal microscope C) Angle spectrum of each substrate with their respective Str value which provide information related to the uniformity of the surface texture. Data represent the means of 4-6 independent batches of substrates with $n=4-10 \pm$ SE. 


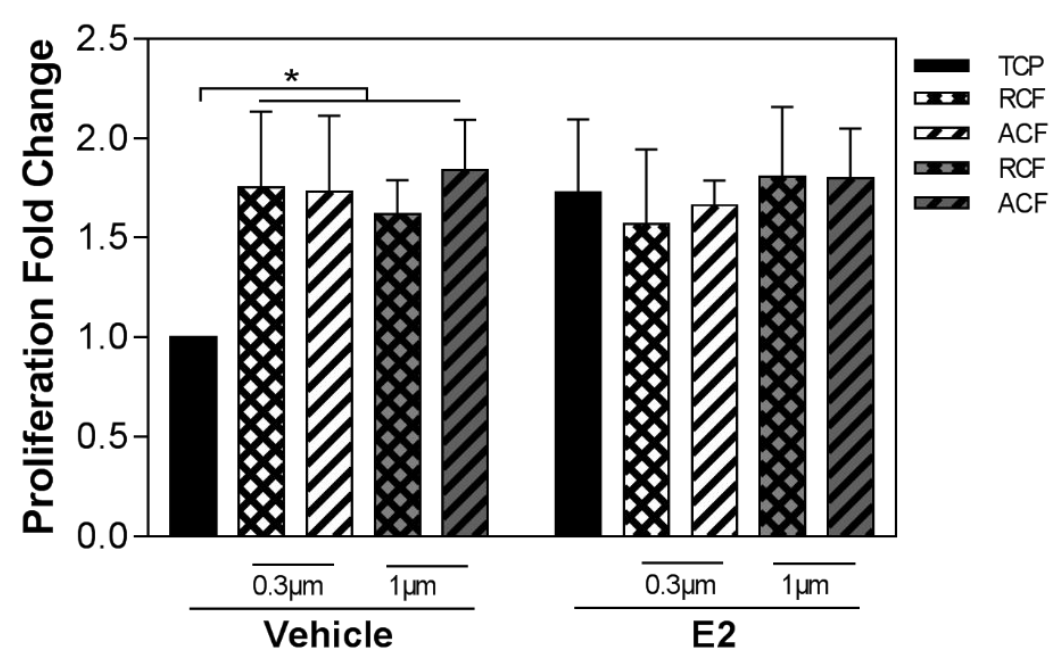

Figure S2-Sn. ER signaling in MCF-7 cells cultured on collagen fibrous substrates of different fibril diameter. Proliferation analysis of the MCF-7 cells treated with 1nM of E2 during cultured on TCP, RCF and ACF substrates. Proliferation analysis of MCF-7 is relative to TCP without estrogen (Vehicle). Data represent the average of 3-4 independent experiments with $n=3-4, S E,{ }^{*} p<0.05$. 


\section{ER transactivation of MCF-7 MVLN cells}

We used a modification of the immortalized ER $(+)$ human mammary epithelial cell line MCF7, (MCF7MVLN) that has previously been transfected with an ERE-luciferase construct. Cells were maintained as mentioned in section 2.1. For this analysis, cells were maintained with $10 \%$ charcoal-stripped fetal bovine serum $72 \mathrm{hrs}$ prior to the cells seeding. Approximately 100,000 cells $/ \mathrm{cm}^{2}$ were seeded in the substrates and cells were treated with and without 1nM Estrogen for $24 \mathrm{hrs}$. To perform the luciferase assay, we used the Luciferase Assay System (E1501, Promega) following the manufacturers' method. Briefly, equal cell quantities were lysate for each culture conditions. A volume of $20 \mu 1$ of cell lysate was mixed with $100 \mu 1$ of Luciferase Assay Reagent and incubated for $60 \mathrm{~min}$ at room temperature. Luminescence was measured using an Analytical Monolight 3010 Luminometer.

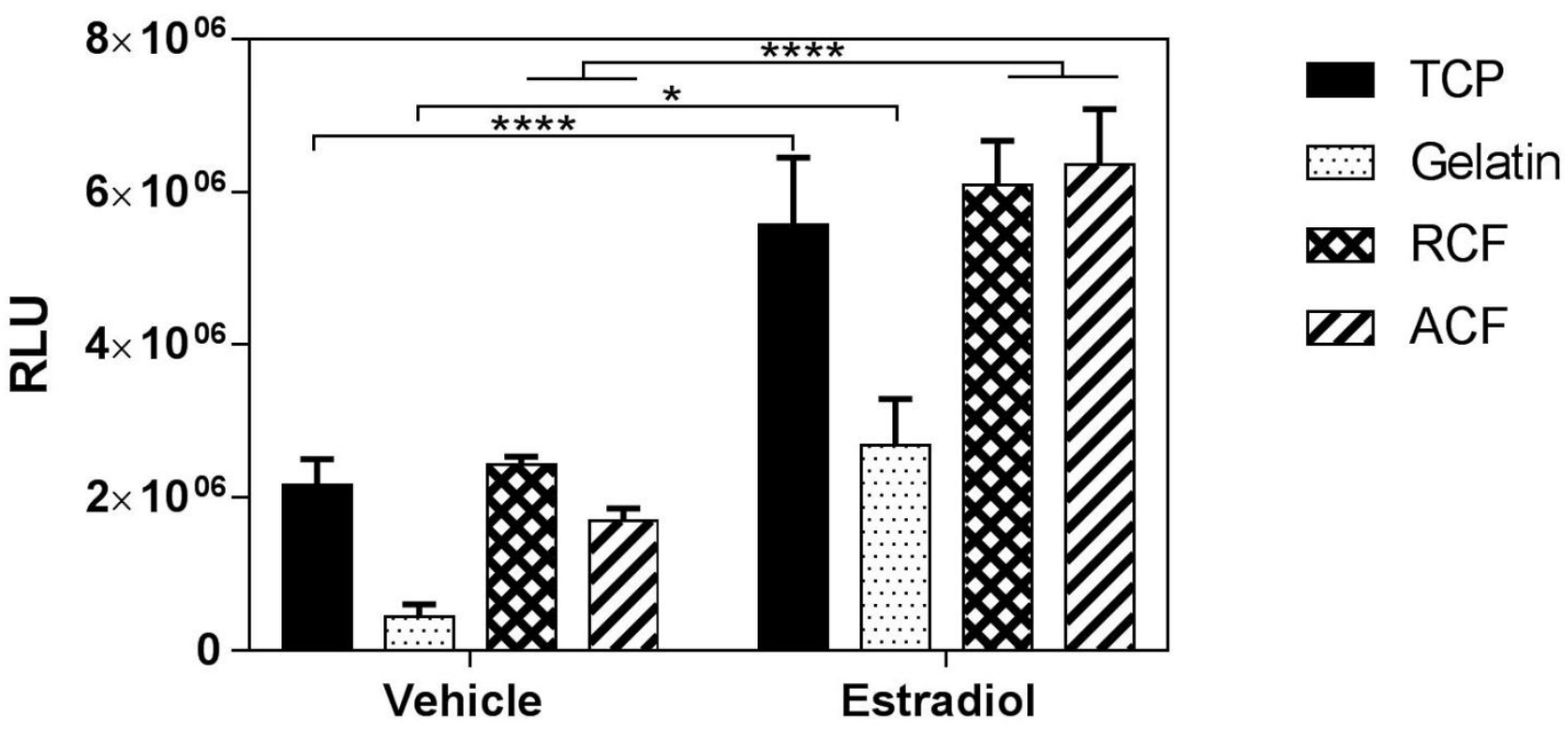

Figure S3-Sn. ER transactivation of MCF-7 MVLN cells. Luminescence expression in different substrates in a hormone restrictive environment used as vehicle and positive control with exogenous estrogen [ $1 \mathrm{nM}]$. Data represent the means of 3 independent experiments with $n=3-4 \pm S E,{ }^{*} p<0.05,{ }^{* *} p<0.01,{ }^{* * *} p<0.001$, $* * * * \mathrm{p}<0.0001$. 


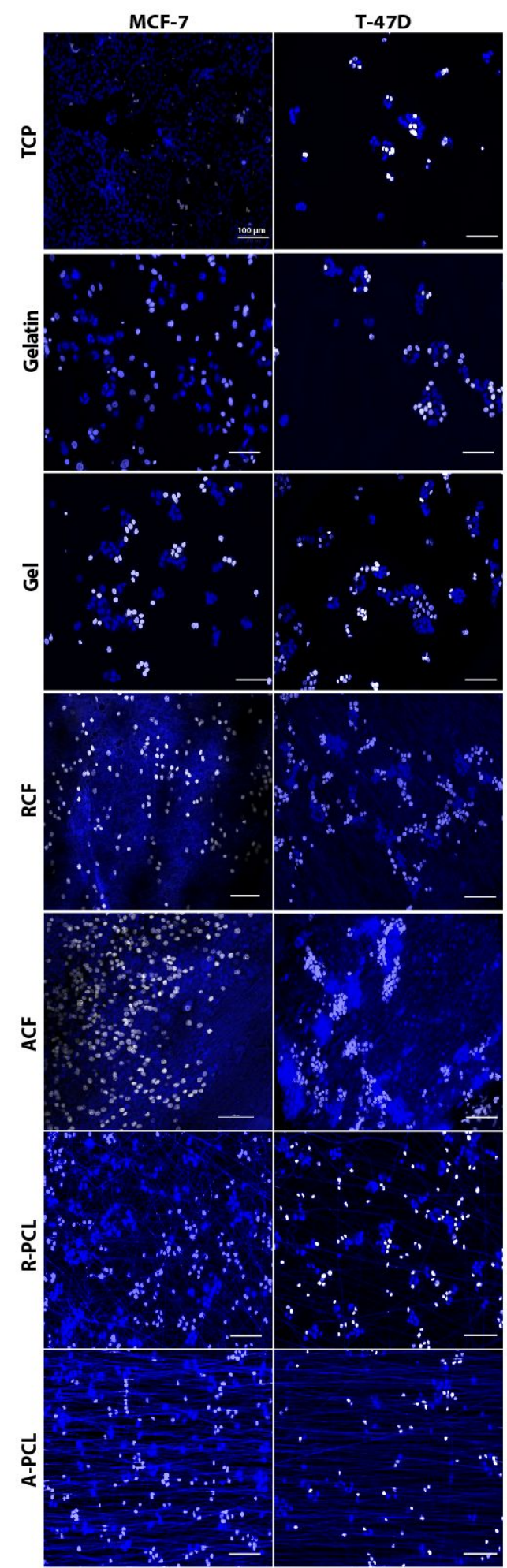

Figure S4-Sn. Representative fluorescent images of MCF-7 and T-47D cells stained with Hoechst and EdU-Alexa 488 to label the nucleus (blue) and cells in S-phase (white) respectively using confocal microscopy. White scale bar represents $100 \mu \mathrm{m}$. 
T-47D
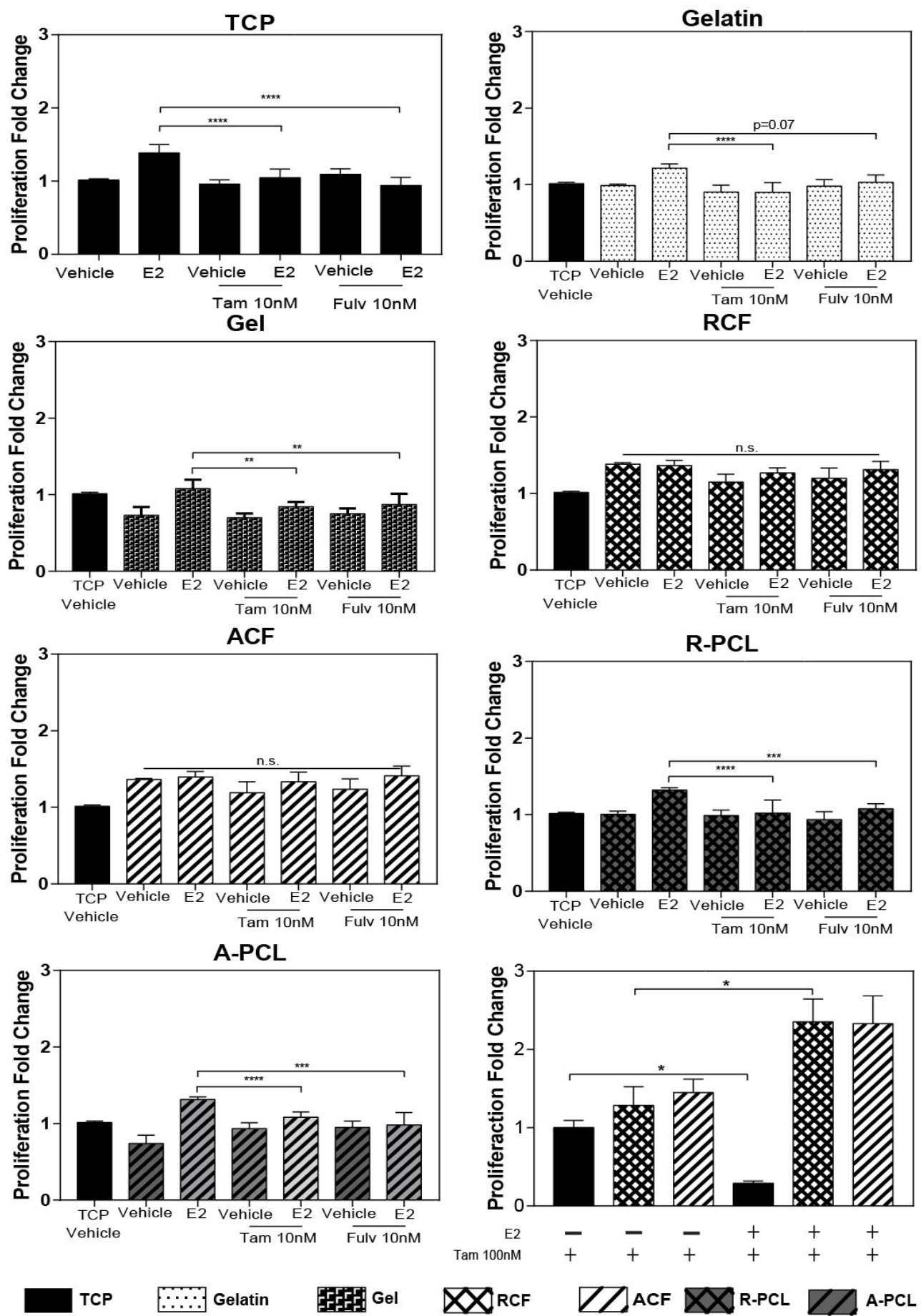

Figure S5-Sn. T-47D sensitivity to ER inhibitors. A-G) Proliferation analysis of the T-47D cells treated with $1 \mathrm{nM}$ of E2 and estrogen receptor signaling inhibitors, $10 \mathrm{nM}$ and $100 \mathrm{nM}$ of Tamoxifen and 10nM of Fulvestrant on (A) TCP, (B) Gelatin, (C) Gel, (D) RCF, (E) ACF (F) R-PCL and (G) A-PCL substrates. H) Proliferation analysis of T-47D cells treated with $1 \mathrm{nM}$ of E2 and $100 \mathrm{nM}$ of Tamoxifen on TCP, RCF and ACF collagen I substrates. Data represent the average of 4 independent experiments with $n=3-4, S E$, $*^{*} \mathrm{p}<0.01$, presented as the fold change relative to the TCP substrate without estrogen (vehicle) shown in graph (A). 
Table S1-Sn. Secretome profile of 640 human factors of MCF-7 and T-47D cells cultured on different substrates. Concentrations were normalized to total cell counts per condition.

\begin{tabular}{|c|c|c|c|c|c|c|}
\hline & \multicolumn{3}{|c|}{ MCF-7 } & \multicolumn{3}{|c|}{$\mathrm{T}-47 \mathrm{D}$} \\
\hline Protein & Plastic [pg/cell] & Random[pg/cell] & Aligned[pg/cell] & Plastic [pg/cell] & Random[pg/cell] & Aligned[pg/cell] \\
\hline 6Ckine & 0 & 0 & 0 & 0 & 0 & 0 \\
\hline Axl & 0 & $1.93 \mathrm{E}-05$ & 0 & 0.000196462 & 0.000121924 & $3.29 \mathrm{E}-05$ \\
\hline BTC & $1.90 \mathrm{E}-05$ & 4.27E-05 & 0 & 0 & 0 & 0 \\
\hline CCL28 & $8.30 \mathrm{E}-05$ & 0.000266113 & $1.39 \mathrm{E}-05$ & $8.44 \mathrm{E}-05$ & $3.04 \mathrm{E}-05$ & 1. 4.0 \\
\hline CTACK & 0 & $1.05 \mathrm{E}-05$ & 0 & $2.52 \mathrm{E}-05$ & 4.44E-06 & 7.64E-06 \\
\hline CXCL16 & 0.010961706 & $6.58 \mathrm{E}-07$ & 0.004145842 & 0.000478942 & 0.000194835 & $8.58 \mathrm{E}-05$ \\
\hline ENA-78 & 0 & 0 & 0 & $1.77 \mathrm{E}-05$ & 0 & $3.63 \mathrm{E}-06$ \\
\hline Eotaxin-3 & 0 & 0.000318674 & 0 & 0 & 0 & $6.66 \mathrm{E}-05$ \\
\hline GCP-2 & $2.16 \mathrm{E}-06$ & $9.94 \mathrm{E}-07$ & $1.01 \mathrm{E}-06$ & 0 & 0 & 0 \\
\hline GRO & $2.71 \mathrm{E}-06$ & $4.26 \mathrm{E}-06$ & $7.81 \mathrm{E}-06$ & 0.000740713 & 0.000251974 & 0.000130775 \\
\hline HCC-1 & $5.52 \mathrm{E}-06$ & $1.12 \mathrm{E}-06$ & $1.26 \mathrm{E}-07$ & 0 & 0 & 4.12E-07 \\
\hline HCC-4 & 4.12E-06 & $4.11 \mathrm{E}-07$ & $5.65 \mathrm{E}-07$ & 0 & $1.03 \mathrm{E}-06$ & $1.51 \mathrm{E}-06$ \\
\hline IL-9 & 0.000348165 & 0.000510156 & 0.000465525 & 0 & 0 & 0 \\
\hline IL-17F & $2.00 \mathrm{E}-05$ & $1.95 \mathrm{E}-06$ & $5.92 \mathrm{E}-06$ & $1.24 \mathrm{E}-05$ & 0 & $2.28 \mathrm{E}-05$ \\
\hline IL-18 BPa & 0 & $2.44 \mathrm{E}-05$ & 0 & 0 & 0 & 0 \\
\hline IL-28A & $7.06 \mathrm{E}-07$ & $1.90 \mathrm{E}-06$ & 8.98E-06 & 0 & 0 & $2.76 \mathrm{E}-06$ \\
\hline IL-29 & 0 & 0.000587334 & 0 & 0 & 0 & 3.94E-05 \\
\hline IL-31 & $5.13 \mathrm{E}-07$ & 5.97E-06 & $6.81 \mathrm{E}-06$ & 0 & 0 & 0 \\
\hline IP-10 & 2.19E-05 & $1.77 \mathrm{E}-05$ & 2.32E-06 & $7.76 \mathrm{E}-06$ & 8.57E-06 & 0 \\
\hline I-TAC & 0 & $2.10 \mathrm{E}-05$ & $5.12 \mathrm{E}-06$ & 0.000459269 & $6.47 \mathrm{E}-05$ & $7.16 \mathrm{E}-05$ \\
\hline LIF & 5.37E-05 & $1.80 \mathrm{E}-05$ & $1.99 \mathrm{E}-05$ & 0 & $4.33 \mathrm{E}-05$ & $2.96 \mathrm{E}-05$ \\
\hline LIGHT & 0.00015514 & $1.40 \mathrm{E}-05$ & $8.51 \mathrm{E}-05$ & 0 & 0 & 0 \\
\hline Lymphotactin & 0 & 0.000101379 & 0 & 0 & 0 & 0 \\
\hline MCP-2 & $4.30 \mathrm{E}-05$ & $5.45 \mathrm{E}-05$ & $1.10 \mathrm{E}-05$ & $1.64 \mathrm{E}-06$ & 0 & 2.79E-06 \\
\hline МCP-3 & $1.45 \mathrm{E}-05$ & $1.78 \mathrm{E}-05$ & $6.89 \mathrm{E}-06$ & $4.27 \mathrm{E}-05$ & $1.22 \mathrm{E}-05$ & $2.11 \mathrm{E}-05$ \\
\hline МСР-4 & $2.15 \mathrm{E}-06$ & $1.64 \mathrm{E}-06$ & 0 & 0 & 0 & 0 \\
\hline $\mathrm{MDC}$ & 4.61E-05 & 4.85E-06 & 4.07E-05 & $2.63 \mathrm{E}-06$ & 0 & $4.56 \mathrm{E}-07$ \\
\hline MIF & 0.008520786 & 0.007784226 & 0.007593434 & 0.001301608 & 0.001125489 & 0.001120685 \\
\hline MIP-3a & $1.08 \mathrm{E}-06$ & $1.12 \mathrm{E}-05$ & 2.91E-06 & 0.000659299 & $3.43 \mathrm{E}-06$ & $6.73 \mathrm{E}-06$ \\
\hline MIP-3b & 7.30E-06 & 7.44E-06 & 4.19E-06 & $1.90 \mathrm{E}-06$ & $2.14 \mathrm{E}-07$ & 0 \\
\hline MPIF-1 & 0 & 0 & $1.05 \mathrm{E}-05$ & 0 & 0 & 0 \\
\hline MSP & $1.16 \mathrm{E}-05$ & 0.000116286 & $1.47 \mathrm{E}-05$ & 0 & 0 & 0 \\
\hline
\end{tabular}




\begin{tabular}{|c|c|c|c|c|c|c|}
\hline NAP-2 & $1.07 \mathrm{E}-06$ & 0 & $3.39 \mathrm{E}-08$ & 0 & $7.65 \mathrm{E}-07$ & $3.98 \mathrm{E}-07$ \\
\hline OPN & 0 & 2.92E-05 & 0 & $2.11 \mathrm{E}-05$ & $1.39 \mathrm{E}-05$ & $3.47 \mathrm{E}-05$ \\
\hline PARC & 4.83E-07 & $3.12 \mathrm{E}-06$ & $1.48 \mathrm{E}-07$ & 0 & 0 & 0 \\
\hline PF4 & 0.000120138 & 0.000193793 & 0.000181868 & 0.000567273 & 0 & 0.000701013 \\
\hline SDF-1a & $3.73 \mathrm{E}-06$ & $8.76 \mathrm{E}-06$ & 4.20E-06 & $1.38 \mathrm{E}-05$ & $5.71 \mathrm{E}-07$ & 4.54E-06 \\
\hline TARC & 0 & $6.59 \mathrm{E}-06$ & $5.00 \mathrm{E}-06$ & $2.49 \mathrm{E}-06$ & 0 & 0 \\
\hline TECK & 0 & 0 & 0 & 8.92E-06 & 4.29E-05 & 0 \\
\hline TSLP & 0 & $5.68 \mathrm{E}-07$ & 0 & $1.44 \mathrm{E}-05$ & $1.30 \mathrm{E}-06$ & $2.77 \mathrm{E}-06$ \\
\hline ADAM8 & 0.005110566 & 0.004903411 & 0.001591621 & 0.005505589 & 0.003365682 & 0.006985099 \\
\hline ADAM12 & 0.000127227 & 0.000133495 & 0 & 0 & 0.000148984 & $5.54 \mathrm{E}-06$ \\
\hline B7-H3 & 0.011828681 & 0.002029799 & 0.004854721 & $3.83 \mathrm{E}-05$ & $6.80 \mathrm{E}-05$ & 5.39E-05 \\
\hline BMPR-IB & 0.002340385 & 0.000880757 & 0.000201072 & $6.19 \mathrm{E}-06$ & 0 & $3.80 \mathrm{E}-06$ \\
\hline Cadherin-4 & 0 & $3.87 \mathrm{E}-05$ & 0 & $4.38 \mathrm{E}-06$ & $1.30 \mathrm{E}-06$ & $7.15 \mathrm{E}-06$ \\
\hline Cadherin-13 & 0.000275221 & 0.000232773 & 0 & 0.000450498 & 0.000405356 & 0.000496997 \\
\hline $\mathrm{CD} 48$ & 0.000988186 & 0.000210545 & $8.73 \mathrm{E}-05$ & 0 & 0 & 0.002054395 \\
\hline CD58 & 0.000521175 & 0.000691421 & 0.000406877 & 0.000583265 & 0.000278279 & 0.000393857 \\
\hline $\mathrm{CD} 84$ & 0.009048062 & 0.004304371 & 0.001038796 & 0 & 0 & 0.000327922 \\
\hline CD99 & 0.001735782 & 0.000160066 & 0.000587323 & 0.000970179 & 0.000617573 & 0.000482439 \\
\hline CD155 & 0.00208413 & 0.001131045 & 0.001074767 & 0.000141568 & 0.000244227 & 0.000155622 \\
\hline CD229 & 0.00148682 & 0.000812297 & 0.000952373 & $8.42 \mathrm{E}-05$ & 0 & 0.000192073 \\
\hline CEACAM-5 & 0.006395449 & 0.010233411 & 0 & 0.001378466 & $1.00 \mathrm{E}-04$ & 0 \\
\hline CF XIV & 0 & 0.000155831 & 0 & 0.000285692 & 0.000256851 & $3.14 \mathrm{E}-05$ \\
\hline Cystatin A & 0 & 0.00026404 & $8.74 \mathrm{E}-05$ & $3.42 \mathrm{E}-06$ & $3.98 \mathrm{E}-07$ & 0 \\
\hline Cystatin B & 0.007151203 & 0.004946537 & 0.003384366 & 0.004199203 & 0.002685246 & 0.003041364 \\
\hline Cystatin E M & $2.05 \mathrm{E}-05$ & 0 & 0 & $4.38 \mathrm{E}-06$ & $2.21 \mathrm{E}-06$ & 0 \\
\hline Desmoglein 2 & 0 & $7.11 \mathrm{E}-06$ & $3.64 \mathrm{E}-06$ & $5.32 \mathrm{E}-05$ & $1.06 \mathrm{E}-07$ & $4.59 \mathrm{E}-05$ \\
\hline DR3 & 0 & $1.36 \mathrm{E}-05$ & 0.000117536 & 0 & 0 & 0.000510103 \\
\hline ErbB4 & $6.34 \mathrm{E}-05$ & $7.20 \mathrm{E}-05$ & 0.000122696 & $2.99 \mathrm{E}-05$ & $1.52 \mathrm{E}-05$ & $1.45 \mathrm{E}-05$ \\
\hline ESAM & $4.54 \mathrm{E}-05$ & $1.85 \mathrm{E}-05$ & $4.76 \mathrm{E}-06$ & 0.000498798 & 0.00040205 & 0.000320252 \\
\hline FGF-21 & 0 & 0 & 4.18E-06 & 0 & $5.76 \mathrm{E}-06$ & 2.04E-06 \\
\hline Galectin-2 & 0 & 0.00036135 & 0 & 0 & 0 & 0 \\
\hline Galectin-9 & 0 & $3.37 \mathrm{E}-07$ & 0 & $8.34 \mathrm{E}-05$ & $5.10 \mathrm{E}-05$ & $5.01 \mathrm{E}-05$ \\
\hline ICOS & 0.000598994 & 0.000382016 & 0.000234296 & 0.000210173 & 0.000194175 & 0.000179098 \\
\hline JAM-A & $2.86 \mathrm{E}-05$ & $9.29 \mathrm{E}-06$ & 0 & $3.49 \mathrm{E}-05$ & 0 & 0 \\
\hline JAM-B & $9.50 \mathrm{E}-05$ & 0.000110024 & 0.000103499 & $3.52 \mathrm{E}-05$ & $3.59 \mathrm{E}-05$ & $1.07 \mathrm{E}-05$ \\
\hline Kallikrein 5 & 0.000798476 & 0.000374498 & 0.000468211 & 0.004511509 & 0.000728994 & 0.001239156 \\
\hline
\end{tabular}




\begin{tabular}{|c|c|c|c|c|c|c|}
\hline Midkine & 0.253987001 & 0.00041344 & 0.125443646 & 0.000465954 & 0.00020138 & $9.74 \mathrm{E}-05$ \\
\hline Pentraxin 3 & 0 & 0 & 0 & 0.000749668 & 0.000599827 & $2.87 \mathrm{E}-05$ \\
\hline Pref-1 & 0.000767555 & 0.000271557 & 0 & 0 & 0 & 0 \\
\hline Siglec-10 & 0.012651864 & 0.012288369 & 0.004633319 & 0.003680959 & 0.001894571 & 0.001046319 \\
\hline SLAM & 0 & 0 & 0 & 0 & 0.000115604 & $3.07 \mathrm{E}-06$ \\
\hline SP-D & 0.000189841 & $3.16 \mathrm{E}-05$ & 0 & 0 & 0 & $1.55 \mathrm{E}-05$ \\
\hline Syndecan-4 & 0.013808231 & $6.09 \mathrm{E}-05$ & 0.003213852 & $2.98 \mathrm{E}-05$ & $2.56 \mathrm{E}-05$ & $2.13 \mathrm{E}-05$ \\
\hline Testican 2 & 0.000411831 & 0.000387871 & 0.000484672 & 4.14E-05 & $5.51 \mathrm{E}-05$ & $5.07 \mathrm{E}-06$ \\
\hline TIM-3 & 0 & 0 & 0 & 0 & 0 & 0 \\
\hline TLR4 & 0 & $2.47 \mathrm{E}-05$ & 0 & 0 & 0 & $2.18 \mathrm{E}-05$ \\
\hline TRAIL & 3.69E-05 & $1.04 \mathrm{E}-05$ & $6.10 \mathrm{E}-06$ & 0 & $5.15 \mathrm{E}-06$ & $1.31 \mathrm{E}-05$ \\
\hline ULBP-1 & $5.74 \mathrm{E}-05$ & 0.000294632 & 0.000411375 & 0 & 0 & 0 \\
\hline ALK-1 & 0.000214778 & 0.000142133 & 0.000143178 & 0.000740357 & 0.000146316 & 0.000660488 \\
\hline B7-H2 & 0.000220916 & $3.17 \mathrm{E}-05$ & 0.0001707 & $1.26 \mathrm{E}-05$ & $3.87 \mathrm{E}-05$ & $2.01 \mathrm{E}-05$ \\
\hline BLAME & 0.001420884 & 0 & 0.000539501 & 0.00034976 & 0 & 0.000771213 \\
\hline BMP-8 & 0.00060293 & 0.000168574 & 0.000225681 & 0 & 0.000113211 & 0.000136924 \\
\hline CD28 & 0.001157784 & 0.000424875 & 0.000101537 & 0.00127186 & 0.000870952 & 0.000812449 \\
\hline Common beta Chain & 0.000816211 & 0.001318341 & 0.000138517 & 0.001807688 & 0.002091997 & 0.002835165 \\
\hline Contactin-1 & 0.000369595 & 0.000103056 & $9.80 \mathrm{E}-05$ & 0.0002453 & 0.00020199 & 0.000285186 \\
\hline Desmoglein-1 & $9.65 \mathrm{E}-05$ & 7.59E-05 & $5.43 \mathrm{E}-05$ & 0.000177805 & 0.000174183 & 0.000106255 \\
\hline Desmoglein-3 & 0.000441037 & 2.89E-05 & 0.00022508 & 0.000400534 & 0.000367737 & 0.000822173 \\
\hline EDAR & 0.000162142 & 0.000122289 & $3.81 \mathrm{E}-05$ & $2.98 \mathrm{E}-05$ & 7.99E-05 & 0.000147055 \\
\hline EphA1 & 0.001589986 & 0.000232589 & 0.00015088 & 0.00040214 & 0.000732073 & 0.000174199 \\
\hline EphB6 & 0.000363843 & $1.62 \mathrm{E}-05$ & $9.27 \mathrm{E}-06$ & 0 & 0.000155134 & 0.000187641 \\
\hline Ephrin-B3 & 0.007239553 & 0.001855438 & 0.0018026 & 0.015763303 & 0.009154985 & 0.009248231 \\
\hline Epiregulin & 0.135490667 & 0.007257528 & 0.089259534 & 0.001005278 & 0.002484546 & 0.003122875 \\
\hline FGF-12 & 0.000374727 & 4.44E-05 & 0.000150267 & 0 & 7.84E-05 & 8.77E-05 \\
\hline FGF-17 & 0.006528459 & 0.002440336 & 0.002878894 & 0.000865701 & 0.000590298 & 0.000684556 \\
\hline FOLR2 & 0.000431423 & 0.000111151 & 0.000132882 & 4.79E-05 & 2.72E-05 & $3.68 \mathrm{E}-05$ \\
\hline Galectin-8 & 0.001763484 & 0.000203471 & 0.000642213 & 0.000961644 & 0.000335519 & 0.00048649 \\
\hline GHR & 0.000159594 & $2.29 \mathrm{E}-05$ & 0.000206979 & $4.76 \mathrm{E}-05$ & $6.96 \mathrm{E}-05$ & $7.46 \mathrm{E}-05$ \\
\hline Glypican 1 & 0.001326034 & $3.42 \mathrm{E}-05$ & 0.000822261 & 0.000636901 & 0.00048832 & 0.000229402 \\
\hline Glypican 5 & 0.003070225 & 0.000406166 & 0.001992964 & 0.000892521 & $8.02 \mathrm{E}-05$ & 0.000458725 \\
\hline IFN-gamma R1 & 0.000129038 & 7.32E-08 & $4.25 \mathrm{E}-05$ & $1.90 \mathrm{E}-05$ & $1.69 \mathrm{E}-05$ & $1.29 \mathrm{E}-05$ \\
\hline IL-22 R alpha 1 & 0.000237988 & $3.02 \mathrm{E}-05$ & 0.000124834 & $5.64 \mathrm{E}-05$ & $5.56 \mathrm{E}-05$ & $5.44 \mathrm{E}-05$ \\
\hline IL-22BP & 0.003857024 & 0 & 0.002651518 & 0.000791193 & 0.001239442 & 0.001608822 \\
\hline
\end{tabular}




\begin{tabular}{|c|c|c|c|c|c|c|}
\hline IL-23 R & 0.000158906 & $1.84 \mathrm{E}-05$ & $6.45 \mathrm{E}-05$ & 0.000132676 & 0.000103272 & 0.00016128 \\
\hline IL-31 RA & 0.000395806 & $4.90 \mathrm{E}-05$ & 0.000178206 & 0.000352044 & 0.000197708 & 0.000161892 \\
\hline IL-7 R alpha & 0.000250446 & $2.41 \mathrm{E}-05$ & 0.00010016 & 0.000335304 & 0.000214894 & 0.000274427 \\
\hline Integrin alpha 5 & 0.285109881 & 0.003636035 & 0.06561573 & 0.014029465 & 0.012278986 & 0.010459795 \\
\hline MDM2 & 0.000354532 & 0.000124745 & 0.000126835 & 0.000179331 & 0.000244067 & 0.00017532 \\
\hline Nectin-1 & 0.013896956 & 0.001566156 & 0.005057764 & 0.002427426 & 0.003953494 & 0.005739358 \\
\hline NKp30 & 0.000544898 & $6.42 \mathrm{E}-05$ & 0.000165399 & 0.000379948 & 0.000472072 & 0.000310315 \\
\hline Nogo Receptor & 0.004665363 & 0.000615457 & 0.000684777 & 0.000720782 & 0.001582291 & 0.001856311 \\
\hline Notch-3 & 0.002212125 & $6.53 \mathrm{E}-05$ & 0.001219768 & 0.000268673 & 0.000615914 & 0.000793656 \\
\hline OSM R beta & 0.018882219 & 0.000531502 & 0.002744773 & 0.021219249 & 0.012887312 & 0.006537596 \\
\hline Prolactin R & 0.000610194 & $6.22 \mathrm{E}-05$ & 0.000364788 & 0.000378753 & 0.000264869 & 0.0003674 \\
\hline RELT & 0.00180182 & $3.94 \mathrm{E}-05$ & 0.001153505 & 0.000339802 & 0.000237588 & 0.000149193 \\
\hline Ryk & 0.000837095 & 0 & 0.000291113 & 0.000166122 & 0.000263948 & 0.000175122 \\
\hline Semaphorin 6D & 0.007999148 & 0.000136461 & 0.00340537 & 0.001225917 & 0.001369039 & 0 \\
\hline Semaphorin 7A & 0.002080393 & 0.000159059 & 0.001095855 & 0.000264224 & 0.000182328 & 0.000236858 \\
\hline Siglec-11 & 0.010475496 & 0.001369927 & 0.003979315 & 0.006882121 & 0.003931952 & 0.001237188 \\
\hline B7-2 & $3.16 \mathrm{E}-06$ & 0 & $4.72 \mathrm{E}-05$ & 0 & 0 & 0 \\
\hline BAFF R & 5.81E-06 & 0 & $1.01 \mathrm{E}-05$ & $1.74 \mathrm{E}-05$ & $3.59 \mathrm{E}-05$ & $1.45 \mathrm{E}-06$ \\
\hline Calcitonin & 0.011768467 & 0.000485162 & 0.004565063 & 0.029027086 & 0.002302538 & 0.018087277 \\
\hline Calsyntenin-1 & 0.00024169 & 0 & 0.000183143 & 0.001601385 & 0.001306462 & 0.00147904 \\
\hline Cathepsin E & $4.06 \mathrm{E}-06$ & 0 & $1.17 \mathrm{E}-05$ & 0.0034933 & 0.002351861 & 0.000797254 \\
\hline cIAP-2 & $6.55 \mathrm{E}-05$ & 0 & 0 & 0.000305192 & $1.55 \mathrm{E}-05$ & 0 \\
\hline CF VII & 0.002074006 & 0 & 0 & 0.000994933 & 0 & 0.001083308 \\
\hline cMASP3 & 0.000514774 & 0 & 0.001268089 & 0.000553619 & 0.000548896 & 0.000108142 \\
\hline Endocan & 4.85E-05 & $7.66 \mathrm{E}-06$ & 0 & 0.000100875 & $2.42 \mathrm{E}-05$ & 4.59E-05 \\
\hline EphA2 & $8.60 \mathrm{E}-05$ & $2.96 \mathrm{E}-05$ & $8.30 \mathrm{E}-06$ & 0.003535818 & 0.001395714 & 0.001800851 \\
\hline EphB4 & 0.008930413 & 0.000360924 & 0.002427367 & $7.10 \mathrm{E}-05$ & $4.88 \mathrm{E}-05$ & $5.99 \mathrm{E}-05$ \\
\hline Ephrin-A4 & 0 & 0.000201667 & 0 & 0 & 0 & 0 \\
\hline FGF-23 & 0 & 0 & 0 & $6.98 \mathrm{E}-05$ & 7.87E-05 & 0.000114993 \\
\hline FGF-5 & 0.000606614 & 0.00057134 & 0.000591012 & 0.001104809 & 0.000559966 & 0.000394883 \\
\hline Flt-3 & $2.00 \mathrm{E}-06$ & $3.76 \mathrm{E}-05$ & 0 & 5.19E-05 & $3.40 \mathrm{E}-05$ & $1.21 \mathrm{E}-05$ \\
\hline GLP-1 & 7.93E-05 & $6.83 \mathrm{E}-05$ & $7.50 \mathrm{E}-05$ & 7.64E-05 & 0 & 0.000105938 \\
\hline Glypican 2 & 0.002009226 & 0.001900219 & 0.000522336 & 0.000564599 & 0.001381628 & 0 \\
\hline GM-CSF Ra & 0.001780939 & 0.001475581 & 0.001852007 & 0.00527426 & 0.002636127 & 0.002815011 \\
\hline GP73 & $4.59 \mathrm{E}-05$ & 0 & $9.75 \mathrm{E}-05$ & 0.000981226 & 0.000383186 & 0.000406164 \\
\hline HTRA2 & 0.000453464 & 0.002966173 & 0.000244059 & 0.006493012 & 0.004883757 & 0.004937045 \\
\hline
\end{tabular}




\begin{tabular}{|c|c|c|c|c|c|c|}
\hline IL-20 Ra & 0 & 0 & 0.001790131 & 0.010408577 & 0.006734025 & 0.010883953 \\
\hline IL-4 Ra & 2.99E-05 & $1.65 \mathrm{E}-05$ & $3.92 \mathrm{E}-05$ & 0.000165752 & 0.000124661 & 7.47E-05 \\
\hline JAM-C & 0.00027698 & $3.39 \mathrm{E}-05$ & $6.04 \mathrm{E}-05$ & 0.000282367 & 0.000205726 & 0.000207803 \\
\hline LH & 0 & 0.000506799 & 4.94E-05 & 0.000419905 & 0.000116441 & 0.000428312 \\
\hline Matrilin-3 & 0.00044201 & 0 & 0.000189078 & 0.000112867 & $8.51 \mathrm{E}-05$ & $3.36 \mathrm{E}-05$ \\
\hline MeprinA & 0.003430952 & 0 & 0 & 0.008195337 & 0.007206062 & 0.005703125 \\
\hline MSP R & 0.000190095 & 0 & 0 & $9.29 \mathrm{E}-05$ & $9.83 \mathrm{E}-06$ & 0 \\
\hline N-Cadherin & 0.005669382 & 0.000979371 & 0.00060942 & 0.000467616 & 0.000127273 & 0.00011849 \\
\hline Neprilysin-2 & 0 & 0.001091107 & 0.002501429 & 0.002854959 & 0.00735922 & 0.001012344 \\
\hline NKp44 & 0 & 0 & 0 & 0.000136431 & $9.02 \mathrm{E}-05$ & 0 \\
\hline PAPP-A & 0.006382193 & 0.001491692 & 0 & 0.008020601 & 0.003409347 & 0.003857726 \\
\hline Pepsinogen II & 0 & 0 & 0 & 0.000614586 & 0.000374426 & 0.000437867 \\
\hline Presenilin 1 & $5.84 \mathrm{E}-05$ & 0 & 0 & $1.96 \mathrm{E}-05$ & 0 & 7.39E-06 \\
\hline PTH & 9.97E-06 & 0 & 0 & 0 & $2.41 \mathrm{E}-05$ & 0 \\
\hline PYY & 0.004850003 & 0.002516645 & 0.002100454 & 0.002530055 & 0.00135829 & 0.002365016 \\
\hline SOX2 & 0 & 0 & 0 & 0.004112138 & 0.004534456 & 0.002130288 \\
\hline TFF3 & 0.005147914 & 0 & 0.022362996 & 0 & 0.000769545 & 0.000317051 \\
\hline TFPI-2 & $8.23 \mathrm{E}-06$ & 0 & 0 & 0.002513231 & 0.002240559 & 0.000582841 \\
\hline TRACP & 0.000671546 & $5.90 \mathrm{E}-05$ & 0.000164943 & 0.001206077 & 0.001423076 & 0.001085515 \\
\hline Ubiquitin+1 & 0.001869162 & 0 & 0.000676942 & 0.000671246 & 0.000282953 & $3.69 \mathrm{E}-05$ \\
\hline $\mathrm{ACE}$ & 0.00331703 & 0.000630545 & 0.000841105 & 0.000506885 & 0.000150072 & 0 \\
\hline Activin RIB & 0.002311822 & 0.000783864 & 0.000448978 & 0.000194951 & 0.000303113 & 0 \\
\hline ADAM23 & 0.01530055 & 0.004206831 & 0.002784287 & 0.000784157 & 0.000183197 & 0.000568094 \\
\hline Artemin & $5.45 \mathrm{E}-05$ & 0 & 0 & 0.000319855 & 0 & 0.000646867 \\
\hline Cardiotrophin-1 & 0.006238373 & 0.003344436 & 0.006572889 & 0.000322547 & 0.000271739 & 0.000238665 \\
\hline Cathepsin V & 0.001640682 & $9.70 \mathrm{E}-05$ & 0.003182107 & 0.00080108 & 0.000431634 & 0.000683469 \\
\hline FABP1 & 0.044893568 & 0 & 0.052309379 & 0.00190818 & 0.002558197 & 0.004114333 \\
\hline FGF-20 & 0 & 0 & 0.000906503 & 0.001124138 & 0.000403651 & 0.00092492 \\
\hline GDF-8 & 0.002695021 & 0.000558071 & 0.001456985 & 0.008099959 & 0.001049107 & 0.006989435 \\
\hline HAI-1 & 0.006626054 & 0.002671755 & 0.001959316 & 0.000391276 & 0.000327195 & 0.000556826 \\
\hline IL-27 Ra & 0.004718196 & 0.000101066 & 0.002361056 & 0 & 0.000389856 & 0.000364154 \\
\hline Insulin R & 0.010171644 & 0.002370277 & 0.003409042 & 0.004034113 & 0.0007706 & 0.00334355 \\
\hline Kallikrein 7 & 0.001024813 & $9.53 \mathrm{E}-05$ & 0.000514352 & $1.29 \mathrm{E}-05$ & $5.42 \mathrm{E}-06$ & $5.83 \mathrm{E}-06$ \\
\hline LIF R alpha & 0.000302611 & $8.53 \mathrm{E}-05$ & 0.000115142 & $1.00 \mathrm{E}-04$ & $7.23 \mathrm{E}-05$ & 4.90E-05 \\
\hline Lipocalin-1 & $2.35 \mathrm{E}-05$ & $5.37 \mathrm{E}-06$ & $1.16 \mathrm{E}-05$ & 0.000743399 & 0.000158523 & 0.000120555 \\
\hline LTbR & 6.19E-05 & $4.50 \mathrm{E}-06$ & $2.05 \mathrm{E}-05$ & 2.99E-05 & $9.37 \mathrm{E}-06$ & $2.49 \mathrm{E}-05$ \\
\hline
\end{tabular}




\begin{tabular}{|c|c|c|c|c|c|c|}
\hline Mesothelin & 0.000994453 & 0.000331557 & 0.000452326 & 0.000118756 & 0.000154101 & 0.000155058 \\
\hline MFRP & $2.65 \mathrm{E}-05$ & 0 & 0.000361665 & 0.000821764 & 0.000491825 & 0.000524608 \\
\hline Neuropilin-2 & 0.001047709 & $9.83 \mathrm{E}-05$ & 0.000260405 & 0 & 4.08E-05 & $5.76 \mathrm{E}-05$ \\
\hline Neurturin & 0.000227571 & 7.36E-05 & $9.80 \mathrm{E}-05$ & 0.000137494 & 0.000219479 & 0.00014077 \\
\hline Nidogen-2 & 0.000136695 & 0 & 0 & $9.02 \mathrm{E}-05$ & 0.000255863 & 0.000333509 \\
\hline Olfactomedin-2 & 0.006522537 & $2.61 \mathrm{E}-05$ & 0.00212283 & $6.64 \mathrm{E}-05$ & 0.000905793 & 0.000387019 \\
\hline p53 & 0.002407725 & 0.000666049 & 0.001117705 & 0.002292616 & 0.001610712 & 0.002478062 \\
\hline PD-ECGF & 0.005899773 & 0 & 0.000443153 & $9.36 \mathrm{E}-05$ & 0.00082361 & 0.000871416 \\
\hline PDGF-CC & 0.001095728 & 0 & 0.000267847 & 0.0011819 & 0.000836252 & $9.44 \mathrm{E}-05$ \\
\hline Progranulin & 0.042712281 & 0.000343223 & 0.01782209 & 0.023543932 & 0.01738024 & 0.008857363 \\
\hline Ret & 0.004551708 & 0 & 0.00330051 & 0.005519341 & 0.002492772 & 0.002705526 \\
\hline ROBO4 & 0.000991049 & 0.000312063 & 0.000234247 & 0 & 0 & 0 \\
\hline Semaphorin 6B & 0 & 0 & 0.000518854 & 0.000807 & 0.000741742 & 0.000844937 \\
\hline Serpin F1 & 0.003874854 & 0.000187827 & 0.001239483 & 0.001200257 & 0.000965283 & 0.000299543 \\
\hline SREC-I & 0.000130175 & 0 & 0 & 0.001273277 & 0.000364571 & 0.0002851 \\
\hline SREC-II & 0 & 0 & 0.000930862 & 0.000537224 & 0.000598342 & 0.000164561 \\
\hline TLR1 & 0.000483866 & $2.08 \mathrm{E}-05$ & 0.000128497 & 0.000223801 & 0.000132067 & $7.96 \mathrm{E}-05$ \\
\hline TLR3 & 0.000297263 & 7.07E-05 & 7.47E-05 & 0.000231093 & 0.000283239 & 8.69E-05 \\
\hline TPP1 & 0.005458561 & 0.000306402 & 0.001605673 & 0.001712322 & 0.00177723 & 0.000920207 \\
\hline TREM-2 & 0.000131788 & $1.25 \mathrm{E}-05$ & $6.33 \mathrm{E}-06$ & $1.21 \mathrm{E}-05$ & 4.73E-05 & 7.27E-05 \\
\hline TrkC & 0.000413905 & 7.39E-05 & $7.64 \mathrm{E}-05$ & 0.000110369 & $3.20 \mathrm{E}-05$ & 7.35E-05 \\
\hline TROY & 0.000194767 & 0 & 0 & 0.000317805 & 0 & 0.000130898 \\
\hline Uromodulin & 0.000160246 & $3.94 \mathrm{E}-05$ & 5.84E-05 & 0.000108379 & 0.000121128 & 0.000218289 \\
\hline XIAP & 0.004451642 & 0.005456913 & 0.004342653 & 0.000755525 & 0.000506843 & 0.000365552 \\
\hline 4-1BB Ligand & 0.000440636 & 0 & 0 & 0 & 0 & 0.000322495 \\
\hline Activin RIIB & 0.000146787 & $1.86 \mathrm{E}-05$ & $2.94 \mathrm{E}-05$ & $2.90 \mathrm{E}-05$ & 0.000112318 & 0.000191584 \\
\hline Aminopeptidase P2 & 7.38E-05 & 0.000437318 & 0 & 0.001603761 & 0.000943503 & 0.001440867 \\
\hline BAMBI & 0.000512917 & $1.15 \mathrm{E}-05$ & 0.000303658 & 0.000468507 & $5.23 \mathrm{E}-05$ & 0.00032688 \\
\hline $\mathrm{BOC}$ & 5.91E-05 & $8.66 \mathrm{E}-05$ & 0 & 0 & 0 & 0 \\
\hline Brevican & $2.34 \mathrm{E}-05$ & $1.03 \mathrm{E}-05$ & $2.00 \mathrm{E}-05$ & $3.12 \mathrm{E}-05$ & $2.48 \mathrm{E}-05$ & 4.53E-05 \\
\hline Carbonic Anhydrase XII & 0.01057601 & 0.001007742 & 0.006251667 & 0.001589853 & 4.90E-05 & 0.002306936 \\
\hline Carboxypeptidase A2 & 4.09E-05 & $9.87 \mathrm{E}-06$ & $3.12 \mathrm{E}-05$ & 0 & $3.31 \mathrm{E}-06$ & 0 \\
\hline CD300c & 0 & 0 & 0 & $2.17 \mathrm{E}-05$ & $2.08 \mathrm{E}-06$ & 7.17E-05 \\
\hline CD320 & 0 & 0.000228447 & 0.000293575 & 0.000858116 & 0.000206716 & 0.00059997 \\
\hline CDNF & 0 & $1.24 \mathrm{E}-06$ & $1.44 \mathrm{E}-06$ & $1.06 \mathrm{E}-05$ & $1.80 \mathrm{E}-05$ & $2.46 \mathrm{E}-05$ \\
\hline $\mathrm{CDO}$ & 0.000290709 & 4.52E-05 & 0.000313013 & 4.24E-05 & 0 & $2.53 \mathrm{E}-05$ \\
\hline
\end{tabular}




\begin{tabular}{|c|c|c|c|c|c|c|}
\hline CHST1 & 0 & 7.56E-06 & 4.75E-05 & 0.000143353 & $1.84 \mathrm{E}-05$ & 0.000131855 \\
\hline CHST4 & 0 & 0 & 0 & 0.000622974 & 0.00052114 & 0.000851974 \\
\hline CILP-1 & 0 & 0 & 0 & $6.49 \mathrm{E}-05$ & 0 & 0.000135477 \\
\hline CNTF R alpha & 0 & 0 & 0 & $2.13 \mathrm{E}-05$ & 0 & $5.05 \mathrm{E}-05$ \\
\hline CRIM1 & 0.00054323 & $1.72 \mathrm{E}-05$ & 0.000271579 & 0.002933523 & 0.001936281 & 0.001048906 \\
\hline CRTAC1 & 0 & 0.000231822 & 0.000109135 & 0 & 0.000193607 & 0.000463766 \\
\hline CXADR & $8.76 \mathrm{E}-05$ & $4.26 \mathrm{E}-05$ & $5.22 \mathrm{E}-05$ & 0.000498716 & 0.000193823 & 0.000351833 \\
\hline Dopa Decarboxylase & $9.56 \mathrm{E}-06$ & $1.59 \mathrm{E}-06$ & $3.75 \mathrm{E}-06$ & $6.38 \mathrm{E}-06$ & 4.34E-06 & 7.92E-06 \\
\hline DPPII & 0.028516732 & 0.004338152 & 0.012925746 & 0.004737805 & 0.005584695 & 0.004215769 \\
\hline DSPG3 & $6.28 \mathrm{E}-05$ & $3.07 \mathrm{E}-05$ & $5.53 \mathrm{E}-05$ & 0 & 7.65E-05 & 0.000203505 \\
\hline EMR2 & $2.80 \mathrm{E}-06$ & $1.77 \mathrm{E}-06$ & $1.15 \mathrm{E}-06$ & $8.54 \mathrm{E}-05$ & $5.60 \mathrm{E}-05$ & $3.48 \mathrm{E}-05$ \\
\hline FCAR & 0 & $9.70 \mathrm{E}-06$ & 0.00019875 & 0.000883288 & 0.000747937 & 0.00063309 \\
\hline FCRL1 & 0.000519385 & 0.000323493 & 0.000186982 & 0.000746396 & 0.000768568 & 0.001094684 \\
\hline FCRL2 & 0 & $8.18 \mathrm{E}-05$ & 0 & 0.000111144 & 0.000150772 & 0.000126588 \\
\hline Gas6 & $5.32 \mathrm{E}-06$ & $1.09 \mathrm{E}-06$ & 8.01E-06 & 3.39E-06 & $2.03 \mathrm{E}-05$ & $2.54 \mathrm{E}-05$ \\
\hline GPR56 & 0.000399028 & $2.56 \mathrm{E}-05$ & 0.000102865 & $6.64 \mathrm{E}-05$ & $1.15 \mathrm{E}-05$ & $1.92 \mathrm{E}-05$ \\
\hline GPVI & 0 & 0 & 0 & $1.62 \mathrm{E}-05$ & $2.05 \mathrm{E}-05$ & 2.92E-05 \\
\hline Hepsin & 0 & 0 & $2.52 \mathrm{E}-06$ & $6.83 \mathrm{E}-05$ & 0.000115314 & 0.00013079 \\
\hline ILT2 & 0 & 0 & $2.62 \mathrm{E}-07$ & $3.46 \mathrm{E}-06$ & $2.22 \mathrm{E}-06$ & 3.03E-06 \\
\hline Jagged 2 & 0 & 0 & 0 & 0.004637047 & 0.00392219 & 0.003851073 \\
\hline Kirrel3 & 0 & 0 & 0 & 0.000219874 & 0.000207682 & 0.000246036 \\
\hline KLF4 & 0.001332149 & 0 & 0 & 0.000908797 & 0.00064963 & 0.001122793 \\
\hline LAIR1 & 5.84E-05 & 0.00025419 & $1.05 \mathrm{E}-05$ & 0.002754666 & 0.000709288 & 0.001627327 \\
\hline LAMP & 0 & $1.45 \mathrm{E}-07$ & 0 & 0.000343835 & 0.000159419 & 0.000303414 \\
\hline LAMP1 & 0.000441965 & 0.000123685 & 0.000331874 & 0.004963268 & 0.004443672 & 0.004792665 \\
\hline MDGA1 & 0 & 0.000143637 & 0 & 0.000250836 & 0.00037744 & $8.45 \mathrm{E}-05$ \\
\hline MIS RII & 0 & $1.31 \mathrm{E}-05$ & 0 & 0.000166465 & 0 & 0.000138703 \\
\hline Neurexin 3 beta & 0 & 0 & 0 & 0 & 0 & $1.78 \mathrm{E}-05$ \\
\hline AMIGO & 0.00199253 & 0.000764782 & 0.000984187 & 0 & 0 & 0 \\
\hline Aminopeptidase LRAP & 0.058982739 & 0.0664978 & 0.030684104 & 0.022344202 & 0.020351308 & 0.01537439 \\
\hline Amnionless & 0.002366138 & 0.000733175 & 0.00051387 & 0 & 0 & 0 \\
\hline Arylsulfatase A & 0.012618276 & 0.011447026 & 0.007656005 & 0.010036693 & 0 & 0.005864331 \\
\hline Bcl-w & $8.14 \mathrm{E}-05$ & $6.86 \mathrm{E}-06$ & 5.92E-06 & 0 & $1.29 \mathrm{E}-05$ & 9.04E-06 \\
\hline CD109 & 0.045581214 & 0.326175939 & 0.025471804 & 0.011065096 & 0 & 0.006939828 \\
\hline CD157 & $1.57 \mathrm{E}-06$ & $1.23 \mathrm{E}-06$ & $5.18 \mathrm{E}-08$ & 8.33E-07 & 0 & $2.28 \mathrm{E}-06$ \\
\hline CD34 & 0.000212101 & $6.67 \mathrm{E}-05$ & $5.81 \mathrm{E}-05$ & 0.000124754 & $6.24 \mathrm{E}-05$ & 0.000129756 \\
\hline
\end{tabular}




\begin{tabular}{|c|c|c|c|c|c|c|}
\hline CD83 & 0 & 3.71E-06 & 0 & 4.83E-05 & 0.000267645 & 0.001200701 \\
\hline CLEC-1 & 0.003911134 & 0.011670163 & 0.005273737 & $8.79 \mathrm{E}-05$ & 0 & 0 \\
\hline CLEC10A & 0 & $4.16 \mathrm{E}-06$ & $9.03 \mathrm{E}-07$ & 0.000192795 & 0.000770506 & 0.000640522 \\
\hline CMG-2 & 0.000110751 & 0.000335886 & 0.000201242 & 0.001540138 & 0.000210925 & 0.001101465 \\
\hline CREG & 0.001356565 & 0.006478708 & 0.002420925 & 0.001108411 & 2.94E-05 & 0.000248292 \\
\hline Cystatin SN & 4.23E-05 & 0 & 0 & 0.00019571 & $7.02 \mathrm{E}-05$ & 0.000105483 \\
\hline Cytokeratin-8 & 0.000981414 & 0.006302003 & 0.002144196 & 0 & 0 & 0.000175609 \\
\hline Dectin-1 & 0.000177492 & 0.000371831 & 4.44E-05 & 0.000140668 & 0 & 0.000129857 \\
\hline Desmocollin-3 & 0.000196561 & 7.61E-05 & 0.000265161 & 0 & 0.000502986 & 0.000445552 \\
\hline Endoglycan & 0.007935364 & 0.018048081 & 0.011207955 & 0 & 0 & 0.036735293 \\
\hline Galectin-4 & 0.0001397 & $1.74 \mathrm{E}-05$ & $5.86 \mathrm{E}-05$ & 0 & 0 & $2.12 \mathrm{E}-06$ \\
\hline HAPLN1 & 0.003270107 & 0.001364325 & 0.002293584 & 0 & 0 & 0.00131624 \\
\hline Jagged 1 & 0.006792496 & 0.001104375 & 0.000618207 & 0 & 0 & 0 \\
\hline Langerin & 0.004608986 & $2.10 \mathrm{E}-05$ & 0.001438192 & 0 & 0 & 0.001058635 \\
\hline Lumican & 0.000592523 & 2.63E-05 & 0.000222784 & 0 & 0 & 0.000104895 \\
\hline Matriptase & 0.00168132 & 0.000407076 & 0.000704808 & 0.003299024 & 0.003498718 & 0.002861017 \\
\hline MEP1B & 0.001065089 & 0.001639074 & 0.000581275 & 0 & 0 & 0 \\
\hline Nectin-3 & $9.18 \mathrm{E}-06$ & 0 & 0 & 4.14E-05 & 3.73E-05 & 0.000122184 \\
\hline OX40 & 0.001443996 & 0.000309303 & 0.000868776 & 0.000131239 & 0 & $8.53 \mathrm{E}-05$ \\
\hline OX40 Ligand & 0.000973919 & 0.00064252 & 0.00059599 & 0 & 0 & 0 \\
\hline p27 & 0.002978483 & 0.00180574 & 0.002334405 & 0.001705417 & 0 & 0.000948924 \\
\hline Pappalysin-2 & 0.000730773 & 0.00020401 & 0.000488643 & 0.000114066 & 0.00010825 & 0.000121999 \\
\hline Plexin B3 & 0.000669283 & $2.54 \mathrm{E}-05$ & 0.000285452 & $4.70 \mathrm{E}-05$ & 0 & $1.64 \mathrm{E}-05$ \\
\hline Plexin D1 & 0.003967625 & 0.000618566 & 0.00166989 & 0 & 0.000593457 & 0.000853697 \\
\hline proGRP & 0.001152643 & 0.00035341 & 0.000465966 & 0.000109265 & 0 & 0.001834846 \\
\hline PSA-total & $3.54 \mathrm{E}-06$ & $2.11 \mathrm{E}-06$ & $3.19 \mathrm{E}-06$ & 0 & 0 & 3.91E-07 \\
\hline Reg1B & 0.00139632 & 0.000988625 & 0.000716462 & 0.000261802 & 0 & 0.000434108 \\
\hline RGM-A & 0.000705714 & 0.000238986 & 0.000459863 & 0 & 0 & 0.000183832 \\
\hline $\mathrm{ROBO} 2$ & 0.002450644 & 0.000193208 & 0.000533674 & 0 & 0 & 0.001449696 \\
\hline Spinesin & 0.000167208 & 0 & 0.000147434 & 0 & 0 & 0.000736614 \\
\hline TWEAK R & 0.000680918 & $1.20 \mathrm{E}-05$ & 0.000254101 & 0 & 0 & 0.000393326 \\
\hline ULBP-3 & 2.95E-05 & $4.58 \mathrm{E}-06$ & 1.73E-05 & $2.51 \mathrm{E}-05$ & 3.49E-05 & 4.14E-05 \\
\hline Activin A & 0.003959308 & 0 & 0.001882796 & 2.11E-05 & 0 & 0 \\
\hline $\mathrm{AgRP}$ & 0.000144672 & 0 & 7.80E-05 & 0 & 0 & $2.30 \mathrm{E}-06$ \\
\hline Angiogenin & 0.001201763 & $1.95 \mathrm{E}-07$ & 0.000881567 & 0.000129281 & 2.09E-05 & 2.34E-05 \\
\hline ANG-1 & 0 & 0 & 0 & 0.000147924 & 0 & 5.03E-05 \\
\hline
\end{tabular}




\begin{tabular}{|c|c|c|c|c|c|c|}
\hline Angiostatin & 0.003107468 & 0 & 0.000869268 & $6.99 \mathrm{E}-05$ & 0 & 0 \\
\hline Cathepsin S & $9.21 \mathrm{E}-06$ & 0 & 0 & 0.001446444 & 0.001107729 & 0.000691487 \\
\hline CD40 & $1.80 \mathrm{E}-05$ & $1.87 \mathrm{E}-07$ & 0 & 0.000101266 & $3.95 \mathrm{E}-05$ & $5.80 \mathrm{E}-05$ \\
\hline Cripto-1 & $1.83 \mathrm{E}-05$ & $2.10 \mathrm{E}-05$ & $3.85 \mathrm{E}-05$ & $4.43 \mathrm{E}-06$ & $2.47 \mathrm{E}-08$ & 0 \\
\hline DAN & 0 & $7.16 \mathrm{E}-05$ & 0 & 0 & $1.24 \mathrm{E}-07$ & 0 \\
\hline DKK-1 & 0.045610683 & 0 & 0.035828093 & 0.005519716 & 0.003110368 & 0.001515244 \\
\hline E-Cadherin & $3.61 \mathrm{E}-05$ & 0.000169251 & $5.86 \mathrm{E}-05$ & 0.000101384 & 0 & 0 \\
\hline EpCAM & 0.000779346 & $1.77 \mathrm{E}-05$ & 0.000233901 & $6.93 \mathrm{E}-05$ & $5.23 \mathrm{E}-05$ & 4.79E-05 \\
\hline FAS L & $1.54 \mathrm{E}-05$ & $4.84 \mathrm{E}-06$ & 4.16E-06 & $2.82 \mathrm{E}-06$ & 0 & 8.70E-06 \\
\hline Fcg RIIBC & $1.59 \mathrm{E}-05$ & 0.000105819 & 0.000175655 & $1.55 \mathrm{E}-05$ & $1.38 \mathrm{E}-05$ & 7.71E-06 \\
\hline Follistatin & 0.001878576 & 0 & 0.000455644 & 0.060608272 & 0.050977465 & 0.020113394 \\
\hline Galectin-7 & $3.71 \mathrm{E}-05$ & 0 & 0 & $3.26 \mathrm{E}-05$ & 0 & 0.000123611 \\
\hline ICAM-2 & 0 & 0 & $1.33 \mathrm{E}-06$ & 0.000106841 & 0.000155318 & 0.000144131 \\
\hline IL-13 R1 & 4.97E-05 & 0.000121346 & 0.00094792 & 0.000641319 & 0 & 0.000310173 \\
\hline IL-13 R2 & 0.000345458 & 0 & $3.67 \mathrm{E}-05$ & 0.002278861 & 0 & 0.000783169 \\
\hline IL-17B & 0 & $4.90 \mathrm{E}-06$ & 0 & 0.000441892 & $8.73 \mathrm{E}-05$ & 0.000162874 \\
\hline IL-2 Ra & $5.97 \mathrm{E}-05$ & 0 & 7.09E-05 & $6.54 \mathrm{E}-06$ & 0 & $4.02 \mathrm{E}-06$ \\
\hline IL-2 Rb & $8.34 \mathrm{E}-05$ & 0 & 0.000374649 & 0.00055599 & 0.000379276 & 0.000239276 \\
\hline IL-23 & 0.000761543 & $5.75 \mathrm{E}-05$ & 0.000429111 & 0 & $1.71 \mathrm{E}-06$ & $1.03 \mathrm{E}-05$ \\
\hline LAP(TGFb1) & 0.003580827 & $2.91 \mathrm{E}-05$ & 0.001563004 & 0.000359869 & 0.000201466 & $9.54 \mathrm{E}-05$ \\
\hline NrCAM & $9.25 \mathrm{E}-05$ & 0 & $1.52 \mathrm{E}-05$ & $7.98 \mathrm{E}-05$ & 0 & $5.17 \mathrm{E}-05$ \\
\hline PAI-1 & 0.000633374 & 0 & 0.001573011 & 0.018002681 & 0.011742311 & 0.009114091 \\
\hline PDGF-AB & 0.001193743 & 0 & 0.000504093 & 0 & 0 & $2.05 \mathrm{E}-06$ \\
\hline Resistin & 0 & 0 & $2.13 \mathrm{E}-05$ & $2.08 \mathrm{E}-05$ & $4.83 \mathrm{E}-06$ & $9.55 \mathrm{E}-06$ \\
\hline SDF-1b & 0 & 0 & 0 & $1.28 \mathrm{E}-05$ & 0 & $3.88 \mathrm{E}-06$ \\
\hline gp130 & 0.002702158 & 0 & 0.002393394 & 0.005405102 & 0.002337939 & 0.002770696 \\
\hline Shh-N & 0 & 0 & 0 & 0.000246646 & 0.000164988 & $9.74 \mathrm{E}-05$ \\
\hline Siglec-5 & $7.90 \mathrm{E}-05$ & 0 & $1.55 \mathrm{E}-05$ & $5.38 \mathrm{E}-05$ & $2.94 \mathrm{E}-05$ & $4.20 \mathrm{E}-05$ \\
\hline IL-1 R4 & 0.000295428 & 0 & 0.000314339 & 0 & 0 & 0.000168095 \\
\hline TGFb2 & 0.000113122 & 0 & 7.14E-05 & 0.000128003 & 0.000113103 & 0.00017972 \\
\hline Tie-2 & 0.000119991 & $1.93 \mathrm{E}-05$ & 0 & 0 & 0 & 0 \\
\hline TPO & 0.000110552 & 0 & 0 & $8.65 \mathrm{E}-05$ & 0.000101541 & 0.000118099 \\
\hline TRAIL R4 & 0 & $1.37 \mathrm{E}-05$ & $2.18 \mathrm{E}-05$ & 0 & 0 & 0 \\
\hline TREM-1 & 0.000492812 & $5.26 \mathrm{E}-06$ & 0.000161096 & $5.78 \mathrm{E}-05$ & 0 & $1.46 \mathrm{E}-05$ \\
\hline VEGF-C & 0 & 0 & 0 & $3.06 \mathrm{E}-05$ & 0 & $2.07 \mathrm{E}-06$ \\
\hline VEGF R1 & 0.000982267 & 0.000164287 & 0.000521876 & 0 & 0 & 0 \\
\hline
\end{tabular}




\begin{tabular}{|c|c|c|c|c|c|c|}
\hline Adiponectin & 0.001782727 & 0.000894212 & 0.000349178 & 0.007807455 & 0 & 0.002930697 \\
\hline Adipsin & 0.000279777 & 0.000139172 & 0.000116189 & $7.83 \mathrm{E}-05$ & $9.14 \mathrm{E}-06$ & $3.80 \mathrm{E}-05$ \\
\hline AFP & 0 & 0 & 0 & 0.00048655 & 0 & 0.000144335 \\
\hline ANGPTL4 & $2.70 \mathrm{E}-05$ & 0 & $9.65 \mathrm{E}-05$ & 0.001807874 & 0.002484855 & 0.001430236 \\
\hline $\mathrm{B} 2 \mathrm{M}$ & 0.009888348 & 0.000109233 & 0.006083269 & 0.001988132 & 0.001037924 & 0.000971335 \\
\hline BCAM & 0.00355759 & 0 & 0.000737669 & 0.002009739 & 0.00016558 & 0.001573434 \\
\hline CA125 & 0.002455814 & 0 & 0.000402684 & 0.00237069 & 0.001626926 & 0.001360892 \\
\hline CA15-3 & 0.001387147 & $6.58 \mathrm{E}-05$ & 0.000700694 & 0.004716462 & 0.001813549 & 0.001776321 \\
\hline CEA & 0.001099994 & 0 & 0.000130354 & 0.00027228 & 0.000121521 & 0.000277814 \\
\hline CRP & $5.47 \mathrm{E}-06$ & 0 & 0 & 0 & 0 & 0 \\
\hline ErbB2 & $3.99 \mathrm{E}-05$ & $1.66 \mathrm{E}-05$ & 0 & $1.29 \mathrm{E}-05$ & 0 & 0 \\
\hline Ferritin & 0.001750797 & 0 & 0 & 4.629632002 & 4.218820005 & 3.279455816 \\
\hline FSH & $9.84 \mathrm{E}-05$ & 0 & 0 & 0.001061526 & 0 & 0.000497342 \\
\hline GROa & 0.000706365 & 0 & 0 & 1.019640008 & 0.335370225 & 0.138212246 \\
\hline $\mathrm{hCGb}$ & 8.97E-05 & $3.18 \mathrm{E}-05$ & 0 & 0.000173394 & 0 & $6.42 \mathrm{E}-06$ \\
\hline IGF-1R & 0 & 0 & 0 & 0 & 0 & 0 \\
\hline IL-1 RII & 0.000238388 & $5.15 \mathrm{E}-05$ & 0 & 0.000142566 & 0 & $4.35 \mathrm{E}-05$ \\
\hline IL-3 & 0 & 0 & 0 & 0.000132529 & 0 & $5.68 \mathrm{E}-05$ \\
\hline IL-18 Rb & 0 & 0 & 0 & $2.36 \mathrm{E}-05$ & 0 & $1.06 \mathrm{E}-05$ \\
\hline IL-21 & 0 & 0.000633883 & 0 & 0.000918451 & 0.000903013 & 0.000634501 \\
\hline Leptin & 0.000200208 & 0 & $9.21 \mathrm{E}-05$ & 0.00053327 & 0.00048851 & 0.000309406 \\
\hline MMP-1 & $1.05 \mathrm{E}-05$ & $5.80 \mathrm{E}-05$ & $5.60 \mathrm{E}-06$ & 0.058345495 & 0.063405811 & 0.033811649 \\
\hline MMP-2 & 0.000313215 & 0.000110204 & 0 & 0.000100216 & $2.71 \mathrm{E}-05$ & $3.21 \mathrm{E}-05$ \\
\hline MMP-3 & $2.47 \mathrm{E}-05$ & 0 & 0 & 0.000218787 & 0.005211708 & 0.000503467 \\
\hline MMP-8 & $4.53 \mathrm{E}-05$ & $2.48 \mathrm{E}-05$ & 0 & 0.000314296 & $6.74 \mathrm{E}-05$ & 0 \\
\hline MMP-9 & 0 & 0 & 0 & $9.27 \mathrm{E}-05$ & $1.31 \mathrm{E}-05$ & $1.72 \mathrm{E}-05$ \\
\hline MMP-10 & $3.23 \mathrm{E}-06$ & $1.04 \mathrm{E}-05$ & $3.89 \mathrm{E}-06$ & 0.001055459 & 0.003704915 & 0.00283058 \\
\hline MMP-13 & $1.43 \mathrm{E}-05$ & 0 & 0 & 0.001746666 & 0.002561545 & 0.001670852 \\
\hline NCAM-1 & 0.000292477 & 0 & 0 & 0.001518581 & 0.004474815 & 0.002652071 \\
\hline Nidogen-1 & 0 & 0 & 0 & 0.00270032 & 0.001019266 & 0.000728028 \\
\hline NSE & 0.00049011 & 0.000366197 & 0.000340144 & 0.02327911 & 0.024617863 & 0.019654303 \\
\hline OSM & 0 & 0 & $1.32 \mathrm{E}-05$ & 0 & 0 & 0 \\
\hline Procalcitonin & 0.002777709 & 0.001541367 & 0.000824241 & 0.00032429 & $1.27 \mathrm{E}-05$ & $9.62 \mathrm{E}-05$ \\
\hline Prolactin & 0.000823739 & 0.000487052 & 0 & 0.003191623 & 0.000578148 & 0.000173807 \\
\hline PSA-free & 0 & 0 & 0 & $2.64 \mathrm{E}-05$ & $2.40 \mathrm{E}-05$ & $9.96 \mathrm{E}-06$ \\
\hline Siglec-9 & $2.53 \mathrm{E}-07$ & 0 & 0 & 0.000158737 & 0 & 0 \\
\hline
\end{tabular}




\begin{tabular}{|c|c|c|c|c|c|c|}
\hline TACE & 0.000287447 & 0 & 0.000394499 & 0.001563603 & 0.001141773 & 0.000850954 \\
\hline Thyroglobulin & 0 & 0 & 0 & 0.157974169 & 0.241828746 & 0.103103757 \\
\hline TIMP-4 & 4.12E-06 & $3.59 \mathrm{E}-06$ & $2.90 \mathrm{E}-06$ & $8.18 \mathrm{E}-05$ & $2.27 \mathrm{E}-06$ & $6.41 \mathrm{E}-06$ \\
\hline TSH & 0 & 0 & 0 & 0.000247409 & $6.41 \mathrm{E}-05$ & 0.000102889 \\
\hline 2B4 & 0 & 0 & 0 & 0.002784344 & 0.001608949 & 0.001520321 \\
\hline ADAM9 & $2.77 \mathrm{E}-05$ & 0 & 0 & 0.00057444 & 0.000374425 & 0.000271099 \\
\hline ANG-2 & 2.99E-05 & 0 & 0 & 0 & 0 & 0 \\
\hline APRIL & $7.38 \mathrm{E}-05$ & 0 & 0 & 0 & 0 & 0 \\
\hline BMP-2 & 0 & 0 & 0 & $8.15 \mathrm{E}-05$ & 0 & 0.000146068 \\
\hline BMP-9 & 0 & 0 & 0 & 0 & 0 & 0 \\
\hline $\mathrm{C} 5 \mathrm{a}$ & $1.24 \mathrm{E}-05$ & 0 & $7.06 \mathrm{E}-06$ & 0.000126578 & $2.33 \mathrm{E}-05$ & $4.30 \mathrm{E}-05$ \\
\hline Cathepsin L & $8.55 \mathrm{E}-05$ & 0 & $1.12 \mathrm{E}-05$ & 0.000429662 & 0.000360011 & 0.000258271 \\
\hline CD200 & $1.05 \mathrm{E}-05$ & 0 & 0 & 0 & 0 & 0 \\
\hline CD97 & 0 & 0 & 0 & 0.00613346 & 0.001842767 & 0.001783398 \\
\hline Chemerin & 0 & 7.92E-05 & 0 & $7.89 \mathrm{E}-05$ & 0 & 0 \\
\hline DcR3 & $1.85 \mathrm{E}-05$ & 0.000206629 & 0 & 0 & 0 & 0 \\
\hline FABP2 & 0 & $7.96 \mathrm{E}-06$ & 0 & 0 & 0 & 0 \\
\hline FAP & 0 & $1.36 \mathrm{E}-05$ & 0 & $3.04 \mathrm{E}-05$ & $1.72 \mathrm{E}-05$ & 0 \\
\hline FGF-19 & 0 & 0.000226698 & 0 & $9.55 \mathrm{E}-06$ & 0 & 0 \\
\hline Galectin-3 & 0.011429003 & 0.011492396 & 0.005259039 & 0.002145145 & 0.001306518 & 0.001216908 \\
\hline HGF R & 0 & $1.81 \mathrm{E}-06$ & $9.66 \mathrm{E}-06$ & 0.000309437 & 0.000270366 & $9.63 \mathrm{E}-05$ \\
\hline IFNab R2 & 0 & 0 & 0 & 0 & 0 & 0 \\
\hline IGF-2 & 0 & 0 & 0 & 0.005179792 & 0 & 0 \\
\hline IGF-2R & 0 & 0 & 0 & 0.002929588 & 0.000853077 & 0.001081293 \\
\hline IL-1 R6 & 0.000394045 & 0 & 0 & 0 & 0 & 0 \\
\hline IL-24 & 0 & 0 & 0 & $1.25 \mathrm{E}-05$ & 0 & 0 \\
\hline IL-33 & $3.27 \mathrm{E}-06$ & 0 & 0 & 0 & 0 & 0 \\
\hline Kallikrein 14 & $3.76 \mathrm{E}-06$ & 0 & 0 & $3.38 \mathrm{E}-05$ & $1.57 \mathrm{E}-05$ & $9.61 \mathrm{E}-06$ \\
\hline Legumain & 0.004032861 & $6.81 \mathrm{E}-05$ & 0.001298922 & 0.012196286 & 0.010387856 & 0.005050046 \\
\hline LOX-1 & $2.42 \mathrm{E}-06$ & 0 & 3.71E-06 & $7.15 \mathrm{E}-06$ & $8.67 \mathrm{E}-07$ & 2.07E-06 \\
\hline MBL & $7.31 \mathrm{E}-07$ & 0 & $1.20 \mathrm{E}-07$ & 0 & 0 & 0 \\
\hline Neprilysin & 0 & 0 & 0 & 0 & 0 & 0 \\
\hline Notch-1 & 0.000105952 & 6.41E-06 & 0 & $7.15 \mathrm{E}-06$ & 0 & 0 \\
\hline NOV & 0 & $2.62 \mathrm{E}-05$ & 0 & 0.002442649 & 0.002031153 & 0.000864675 \\
\hline Osteoactivin & $3.16 \mathrm{E}-07$ & $2.97 \mathrm{E}-05$ & $1.18 \mathrm{E}-05$ & 0.000734235 & 0.000332079 & 0.000291659 \\
\hline PD-1 & 4.60E-05 & $3.26 \mathrm{E}-05$ & $1.77 \mathrm{E}-05$ & $1.27 \mathrm{E}-05$ & 0 & 0 \\
\hline
\end{tabular}




\begin{tabular}{|c|c|c|c|c|c|c|}
\hline PGRP-S & $1.11 \mathrm{E}-06$ & $6.52 \mathrm{E}-07$ & 0 & 0 & 0 & 0 \\
\hline Serpin A4 & 0.000231728 & 0.00012343 & $5.18 \mathrm{E}-05$ & 0.00016913 & $3.42 \mathrm{E}-05$ & $1.80 \mathrm{E}-05$ \\
\hline sFRP-3 & 0 & 4.10E-05 & 7.84E-05 & 0 & 0 & 0 \\
\hline Thrombomodulin & $5.41 \mathrm{E}-05$ & $2.75 \mathrm{E}-05$ & 0.000214688 & 0.000338776 & 0.000512365 & 0 \\
\hline TLR2 & $6.67 \mathrm{E}-05$ & $5.20 \mathrm{E}-05$ & $2.22 \mathrm{E}-05$ & 0 & 0 & 0 \\
\hline TRAIL R1 & $2.72 \mathrm{E}-06$ & 0 & 0 & 0 & $5.82 \mathrm{E}-05$ & 0 \\
\hline Transferrin & 0.018360541 & $1.12 \mathrm{E}-05$ & $1.33 \mathrm{E}-05$ & 0.000711822 & 0.001036633 & 0 \\
\hline WIF-1 & 0.000325093 & $6.09 \mathrm{E}-05$ & 0.000211501 & $1.27 \mathrm{E}-05$ & 0 & 0 \\
\hline ACE-2 & 0 & 0 & 0 & 0.073631105 & 0 & 0.052998401 \\
\hline Albumin & 0.00778894 & 0.000269114 & 0 & 0.000808831 & 0.002180922 & 0 \\
\hline AMICA & 0 & 0 & 0 & 0.000810248 & 0.000571533 & 0.000845506 \\
\hline ANG-4 & 0 & $4.18 \mathrm{E}-05$ & 0 & 0.001572274 & 0.000301362 & 0.00011876 \\
\hline BAFF & 0 & 0 & 0 & 5.47E-05 & $1.53 \mathrm{E}-05$ & 8.48E-06 \\
\hline CA19-9 & 0.003617787 & 0.003197029 & 0.002885509 & 0.001182469 & 0.000493692 & 0.000800414 \\
\hline CD163 & 0 & 0 & 0 & 0.000141686 & $5.31 \mathrm{E}-05$ & 3.07E-05 \\
\hline Clusterin & 0.022212604 & 0 & 0.012871108 & 0.000314812 & 0.000233362 & 0.000130811 \\
\hline CRTAM & 0 & 0 & 0 & $2.59 \mathrm{E}-05$ & 7.84E-05 & 8.79E-05 \\
\hline CXCL14 & 0.009904579 & 0.000495612 & 0.005741473 & 0.000355057 & 0.000146421 & 0.000136745 \\
\hline Cystatin C & 0.035778199 & 0 & 0.019976659 & 0.002488276 & 0.002862301 & 0.000937887 \\
\hline Decorin & $6.12 \mathrm{E}-06$ & 0 & 0 & $3.07 \mathrm{E}-06$ & $8.12 \mathrm{E}-06$ & $9.51 \mathrm{E}-06$ \\
\hline Dkk-3 & 0 & 0 & 0 & $3.82 \mathrm{E}-07$ & 0 & 0 \\
\hline DLL1 & 0.00013907 & $1.71 \mathrm{E}-05$ & 0 & 0 & 0.000485762 & 0.000454071 \\
\hline Fetuin A & 0.00299211 & 0.002130527 & 0 & 0.00530259 & 0 & 0.003424329 \\
\hline $\mathrm{aFGF}$ & 0.000838838 & 0.000952604 & 0.004713428 & 0.030846547 & 0.02105281 & 0.049331354 \\
\hline FOLR1 & 0 & 0 & 0 & 0.000241737 & 0.000146782 & $9.52 \mathrm{E}-05$ \\
\hline Furin & 0.011179859 & 0.000497059 & 0 & 0.000539503 & 0.000531038 & 4.69E-05 \\
\hline GASP-1 & 0 & 0 & 0 & 0.00013344 & 0.000163395 & 0.000262958 \\
\hline GASP-2 & 0 & 0 & 0 & $9.88 \mathrm{E}-05$ & $3.69 \mathrm{E}-05$ & $3.05 \mathrm{E}-05$ \\
\hline G-CSF R & 0 & 0 & 0 & 0 & 0 & 0 \\
\hline HAI-2 & 0.009798021 & $1.38 \mathrm{E}-05$ & 0.005987716 & 0.003561417 & 0.001571826 & 0.000541432 \\
\hline IL-17B R & 0 & 0.00101103 & 0 & 0.00148263 & 0.000577768 & 0.000378903 \\
\hline IL-27 & $1.86 \mathrm{E}-05$ & 0 & 7.62E-06 & $7.90 \mathrm{E}-05$ & $6.47 \mathrm{E}-05$ & $6.30 \mathrm{E}-05$ \\
\hline LAG-3 & 0 & 0 & 0 & 0 & 0 & $2.59 \mathrm{E}-05$ \\
\hline LDL R & 0.000651326 & $2.00 \mathrm{E}-06$ & 0.000494704 & 0.000276563 & 0.00028293 & $8.80 \mathrm{E}-05$ \\
\hline Pepsinogen I & $4.23 \mathrm{E}-05$ & $1.07 \mathrm{E}-05$ & $1.29 \mathrm{E}-05$ & $3.59 \mathrm{E}-06$ & $2.65 \mathrm{E}-06$ & $5.81 \mathrm{E}-06$ \\
\hline RANK & 0 & 0 & 0 & 0.000184985 & $2.64 \mathrm{E}-05$ & $8.12 \mathrm{E}-05$ \\
\hline
\end{tabular}




\begin{tabular}{|c|c|c|c|c|c|c|}
\hline RBP4 & $8.15 \mathrm{E}-05$ & $3.15 \mathrm{E}-07$ & 0 & $2.20 \mathrm{E}-05$ & 0.000115374 & 0 \\
\hline SOST & 0 & 0 & 0 & $1.38 \mathrm{E}-05$ & 0 & 0 \\
\hline Syndecan-1 & 0.003744759 & 0 & 0.001119426 & 0.00065832 & 0.000242542 & 0.000133602 \\
\hline TACI & 0 & 0.000678581 & 0.000185487 & 0.000997995 & 0 & 0.000285925 \\
\hline TFPI & 0.00346966 & 0 & 0.000226001 & 0.002016915 & 0.000764216 & 0.000452115 \\
\hline TSP-1 & 0.110301963 & 0.00082934 & 0.0610875 & 0.045841868 & 0.031058356 & 0.021862732 \\
\hline TRAIL R2 & 9.92E-07 & 0 & 0 & $2.42 \mathrm{E}-06$ & $6.10 \mathrm{E}-06$ & $2.07 \mathrm{E}-06$ \\
\hline TRANCE & 0 & 0 & 0 & 0.01067603 & 0.001387601 & 0.001391079 \\
\hline Troponin I & 4.20E-05 & $1.29 \mathrm{E}-05$ & 0 & 0 & 0 & 0 \\
\hline uPA & 0 & $3.45 \mathrm{E}-06$ & 0 & 0.001409484 & 0.000584554 & 0.00040156 \\
\hline VE-Cadherin & 0.019143729 & 0.001369865 & 0.003286062 & 0.001056223 & 0 & $2.61 \mathrm{E}-05$ \\
\hline WISP-1 & 0 & 0 & 0 & 0.00331976 & 0.000885959 & 0.000969595 \\
\hline ANGPTL3 & 0.006891579 & 0.001102284 & 0.000541599 & 8.32E-05 & $1.03 \mathrm{E}-05$ & $2.13 \mathrm{E}-05$ \\
\hline bIG-H3 & 0.004166892 & 0.000638745 & 0.001487856 & 0.007013254 & 0.002696112 & 0.001028284 \\
\hline CA9 & 0.001435615 & 0.000924088 & 0.00140243 & 0 & 0 & 0 \\
\hline Cathepsin B & 0.001681944 & 0 & 0 & 0.000484511 & 0.001066104 & 0.000132432 \\
\hline CD23 & 0.001575506 & 0.001221179 & 0.001169005 & 7.14E-06 & 0 & 0 \\
\hline CHI3L1 & 0.000909074 & 0.000578518 & 0.00029173 & 0.000873196 & 0.000329988 & 0.000163557 \\
\hline CTLA4 & 0.000540612 & 0.007085799 & 0 & $8.27 \mathrm{E}-05$ & 0 & $9.01 \mathrm{E}-05$ \\
\hline Dkk-4 & 0.000595943 & 0.00239353 & 0 & 0.002479823 & 0.000508842 & 0.002311102 \\
\hline DPPIV & 0.000851109 & 0.000869909 & 0.000374494 & 0.00141747 & 0.0004624 & 0.000528184 \\
\hline EDA-A2 & 0.001092519 & 0.003161159 & 0 & 0 & $6.17 \mathrm{E}-06$ & 0 \\
\hline Epo R & 0.00033256 & 0.000491597 & 0 & 0 & 0 & $2.90 \mathrm{E}-06$ \\
\hline FGF-6 & 0 & 0.000506456 & 0 & 0.000237491 & 0 & $6.84 \mathrm{E}-05$ \\
\hline FGF-9 & 0 & 0.002610557 & 0 & 0 & 8.30E-06 & 0 \\
\hline Gas 1 & 0 & 0.00011804 & 0 & $2.43 \mathrm{E}-05$ & $2.88 \mathrm{E}-05$ & $1.08 \mathrm{E}-05$ \\
\hline IGFBP-5 & 0.003081159 & 0.005221513 & 0 & 0 & 0 & 0 \\
\hline IL-1 F5 & $5.18 \mathrm{E}-06$ & 0.007573985 & 0 & 0 & 0 & 0 \\
\hline IL-1 F6 & 0 & 0.003980955 & 0 & 0 & 0 & 0.00031326 \\
\hline IL-1 F7 & 0.002168528 & 0.002152591 & 0.001909852 & 0.001261756 & 0.000335654 & 0 \\
\hline IL-1 F8 & $7.56 \mathrm{E}-05$ & $2.88 \mathrm{E}-05$ & $3.75 \mathrm{E}-05$ & $2.52 \mathrm{E}-06$ & 0 & 0 \\
\hline IL-1 F9 & 0 & 0.009084126 & 0 & 0 & 0.000952269 & 0 \\
\hline IL-1 F10 & 0.039990961 & 0 & 0.002013164 & 0.008789499 & 0 & 0.00439249 \\
\hline IL-1 R5 & 0.000486926 & $3.58 \mathrm{E}-05$ & 3.30E-05 & $6.71 \mathrm{E}-05$ & 0 & $3.27 \mathrm{E}-05$ \\
\hline IL-17C & 0 & $6.96 \mathrm{E}-05$ & 0 & $3.43 \mathrm{E}-05$ & $6.30 \mathrm{E}-05$ & $3.12 \mathrm{E}-05$ \\
\hline IL-18 & 0.000658225 & 0 & 0.000862767 & 0.000490291 & 0.000552531 & 0.001493465 \\
\hline
\end{tabular}




\begin{tabular}{|c|c|c|c|c|c|c|}
\hline IL-20 & 0.000471333 & 0.000171125 & 0 & 0 & 0 & 0 \\
\hline IL-34 & $2.75 \mathrm{E}-05$ & $9.10 \mathrm{E}-05$ & $1.24 \mathrm{E}-05$ & 0.000134887 & $6.96 \mathrm{E}-05$ & $9.47 \mathrm{E}-05$ \\
\hline IL-5 Ra & 0.005459321 & 0.004865482 & 0.002127054 & 0.002521183 & 0 & 0.002210827 \\
\hline IL-10 Ra & 0 & 0 & 0 & 0.006412606 & 0 & 0.003065107 \\
\hline Layilin & 0.002615824 & 3.09E-05 & 0.000222416 & $9.26 \mathrm{E}-05$ & $1.47 \mathrm{E}-05$ & 5.87E-05 \\
\hline Leptin R & 0 & 0 & 0.007932146 & 0 & 0.000233816 & 0 \\
\hline Marapsin & 0 & 0 & 0 & $9.42 \mathrm{E}-05$ & 0 & $2.18 \mathrm{E}-06$ \\
\hline Mer & 0.000262656 & 0.000274764 & 0 & 0 & 0 & 0 \\
\hline MMP-7 & 0.000225989 & 0.000302332 & 0.000895543 & 0 & $6.66 \mathrm{E}-05$ & 0.00019326 \\
\hline P-Cadherin & 0.002322747 & 0.000128082 & 0.001033162 & 0.002575683 & 0.001139733 & 0.000712124 \\
\hline Prostasin & 0.00020527 & 0 & 0 & $9.88 \mathrm{E}-05$ & 0 & 0.000113537 \\
\hline PSMA & 0.130174089 & 0 & 0.019704984 & 0.001220284 & 0 & 0.001048651 \\
\hline SIGIRR & 0.003307386 & 0.000307165 & 0.000705745 & 0.002181547 & 0.000898324 & 0.001468504 \\
\hline TGFb RIII & 0.006011761 & 0.001203504 & 0 & 0.000372785 & 7.74E-05 & $1.92 \mathrm{E}-05$ \\
\hline $\mathrm{TF}$ & 4.93E-06 & 0 & $2.30 \mathrm{E}-05$ & 0.000658953 & 0.000648683 & 0.000480656 \\
\hline TWEAK & 0.001703009 & 0.002874718 & 0.002060775 & 0.000121556 & $2.83 \mathrm{E}-05$ & 0 \\
\hline ADAMTS13 & 0.003537097 & 0.00468791 & 0.005893989 & 0 & 0 & 0 \\
\hline Aggrecan & 0.000274847 & 0.0001028 & 0.00037302 & 0 & $6.68 \mathrm{E}-05$ & $1.94 \mathrm{E}-05$ \\
\hline Angiotensinogen & 0.006352894 & 0.004048718 & 0.004901466 & 0.002680974 & 0.000257424 & 0.004070437 \\
\hline B7-H1 & 0.000143113 & 0.00014476 & 0.000191749 & 0 & 0 & 0 \\
\hline BMPR-IA & 0.003101384 & 0.002905451 & 0.004216167 & 0 & 0.00026829 & $6.01 \mathrm{E}-05$ \\
\hline BMPR-II & 0.01163218 & 0.005735094 & 0.008597741 & 0 & 0 & 0 \\
\hline Cadherin-11 & $5.64 \mathrm{E}-05$ & 7.89E-05 & $9.49 \mathrm{E}-05$ & 0.001587325 & 0 & 0.001908003 \\
\hline $\mathrm{CD} 27$ & $6.63 \mathrm{E}-05$ & 2.79E-05 & 0.000159647 & 0 & 0 & 0 \\
\hline CD6 & 0.029365695 & 0.012943908 & 0.021769463 & 0.008687641 & 0.005330973 & 0.006316406 \\
\hline Ck beta $8-1$ & 0.00207113 & 0.003076889 & 0.002365791 & 0 & 0.000122926 & 0 \\
\hline $\mathrm{CNTF}$ & $4.16 \mathrm{E}-05$ & 0 & 0.000302318 & 0.037617034 & 0.042020945 & 0.016807195 \\
\hline DNAM-1 & 0.000395073 & 0.000627875 & 0.000492596 & 0.000313485 & 0.000604263 & 0 \\
\hline EMMPRIN & 0.001162493 & 0.000306554 & 0.000609595 & 0.000585648 & 0.00052823 & 0.000503159 \\
\hline FLRG & 0.001036503 & $4.21 \mathrm{E}-05$ & 0.000684139 & $9.98 \mathrm{E}-05$ & 0 & 0 \\
\hline Follistatin-like 1 & 0.000593359 & 0.000401781 & 0.000516308 & 0 & 0.000505061 & 0 \\
\hline Fractalkine & 0.001914538 & 0.001687211 & 0.002066383 & 0.002085581 & 0.004289379 & 0.004248438 \\
\hline Galectin-1 & 0.003039908 & 0.002609911 & 0.001995908 & 0.000610813 & 0.00041852 & 0.000383475 \\
\hline GITR L & 0.001208486 & 0.000414988 & 0.000655107 & 2.07E-05 & $1.44 \mathrm{E}-05$ & 4.67E-05 \\
\hline Granulysin & 0.000535393 & 0.000276436 & 0.000334456 & 0.000710113 & 0.000210084 & 0.000507015 \\
\hline IL-1 R3 & 0.002171026 & 0.000212623 & 0.001204889 & 0 & 0 & 0 \\
\hline
\end{tabular}




\begin{tabular}{|c|c|c|c|c|c|c|}
\hline IL-15 R & 4.14E-05 & $6.31 \mathrm{E}-06$ & $3.23 \mathrm{E}-05$ & $8.71 \mathrm{E}-05$ & $3.59 \mathrm{E}-05$ & $3.82 \mathrm{E}-05$ \\
\hline IL-17E & 0.000628874 & 0.000191503 & 0.000319193 & 0 & 0.000334387 & 0 \\
\hline IL-32 alpha & 4.62E-07 & $5.14 \mathrm{E}-06$ & $1.42 \mathrm{E}-05$ & $2.80 \mathrm{E}-05$ & $3.42 \mathrm{E}-05$ & $1.94 \mathrm{E}-05$ \\
\hline L1CAM-2 & 0 & 0 & 0.001875928 & 0.000438747 & 0.000209661 & 0.000267912 \\
\hline LRIG3 & 0.003802487 & 0.002354407 & 0.002488552 & 0.003222634 & 0.001727712 & 0.001583352 \\
\hline LRP-6 & 0 & 0 & 0.001068121 & 0 & 0.001209078 & 0.00023494 \\
\hline MEPE & 0.004433132 & 0.002067192 & 0.002560173 & 0.002992616 & 0.001396811 & 0.001450054 \\
\hline Nectin-4 & 0.000516549 & 0.000209536 & 0.000410702 & 0.000507581 & 0.000450713 & 0.000426246 \\
\hline Periostin & 0.000121468 & 0 & $4.82 \mathrm{E}-05$ & 0.000424129 & 0.001551609 & 0.002042537 \\
\hline Persephin & 0 & 0 & 0.000334398 & 0.001568229 & 0.00130065 & 0.001164063 \\
\hline Renin & 0 & $5.86 \mathrm{E}-07$ & $1.38 \mathrm{E}-06$ & 0 & 0 & 0 \\
\hline RGM-B & 0.000437377 & 2.19E-05 & 0.000268313 & 0 & 0 & 0 \\
\hline ROBO3 & 0.000307117 & 4.01E-06 & 0.000148022 & $7.00 \mathrm{E}-05$ & $8.61 \mathrm{E}-05$ & $8.68 \mathrm{E}-05$ \\
\hline S100A8 & 8.64E-05 & $6.40 \mathrm{E}-05$ & 0 & 0.000326024 & 0.001435112 & 0.000846418 \\
\hline Siglec-7 & $5.43 \mathrm{E}-05$ & 0 & $3.63 \mathrm{E}-05$ & $8.60 \mathrm{E}-05$ & 0.000157835 & 0 \\
\hline Syndecan-3 & 0.008057245 & 0.002860222 & 0.004306003 & $8.53 \mathrm{E}-05$ & 0 & 0 \\
\hline Thrombospondin-2 & 0.001588238 & 0.000613771 & 0.00186583 & 0 & 0.000504095 & $1.03 \mathrm{E}-05$ \\
\hline Thrombospondin- 5 & 8.69E-06 & 0 & $2.52 \mathrm{E}-05$ & 0 & 0 & 0 \\
\hline Tie-1 & 0.000238412 & $3.87 \mathrm{E}-05$ & 0.000218236 & 0 & 0 & 0 \\
\hline ULBP-2 & 0.000119245 & $3.74 \mathrm{E}-05$ & 0.000143839 & 0 & $1.72 \mathrm{E}-05$ & 0 \\
\hline $\mathrm{AR}$ & 0.001518945 & $6.32 \mathrm{E}-06$ & 0.002827001 & $9.54 \mathrm{E}-05$ & 0.000119098 & 0.000113978 \\
\hline BDNF & $8.29 \mathrm{E}-07$ & 0 & $1.12 \mathrm{E}-06$ & $1.74 \mathrm{E}-05$ & $5.72 \mathrm{E}-06$ & 4.42E-06 \\
\hline bFGF & $6.68 \mathrm{E}-05$ & 0 & $1.10 \mathrm{E}-05$ & $6.56 \mathrm{E}-06$ & 0 & $2.89 \mathrm{E}-06$ \\
\hline BMP-4 & $3.81 \mathrm{E}-05$ & 0 & $6.16 \mathrm{E}-06$ & 0.000216804 & $9.67 \mathrm{E}-05$ & 5.94E-05 \\
\hline BMP-5 & 0 & 0 & 0 & 0.001066245 & 0 & 0 \\
\hline BMP-7 & 4.27E-05 & $3.16 \mathrm{E}-06$ & 0 & 0 & 0 & $2.63 \mathrm{E}-05$ \\
\hline b-NGF & $5.70 \mathrm{E}-07$ & 0 & $1.79 \mathrm{E}-07$ & 0 & 0 & 0 \\
\hline EGF & 0 & $2.34 \mathrm{E}-07$ & 0 & $1.37 \mathrm{E}-07$ & $1.78 \mathrm{E}-07$ & $1.57 \mathrm{E}-07$ \\
\hline EGF R & $6.85 \mathrm{E}-05$ & $8.30 \mathrm{E}-06$ & $2.10 \mathrm{E}-05$ & 0.001802551 & 0.001692273 & 0.00125058 \\
\hline EG-VEGF & $9.08 \mathrm{E}-06$ & 0 & $1.34 \mathrm{E}-06$ & $1.32 \mathrm{E}-05$ & 0 & $1.71 \mathrm{E}-05$ \\
\hline FGF-4 & 0 & 0.000290323 & 0.000211379 & 0 & $3.89 \mathrm{E}-05$ & 7.40E-06 \\
\hline FGF-7 & 0 & $3.79 \mathrm{E}-06$ & 0 & 0 & 4.62E-06 & 0 \\
\hline GDF-15 & 0.002050107 & 2.93E-05 & 0.001317968 & 0.002473174 & 0.002006363 & 0.001140955 \\
\hline GDNF & 0 & $8.74 \mathrm{E}-07$ & 0 & 0 & $1.84 \mathrm{E}-05$ & 0 \\
\hline $\mathrm{GH}$ & $3.69 \mathrm{E}-05$ & $2.68 \mathrm{E}-05$ & $5.38 \mathrm{E}-06$ & $2.43 \mathrm{E}-05$ & $2.26 \mathrm{E}-06$ & $1.95 \mathrm{E}-05$ \\
\hline HB-EGF & $1.17 \mathrm{E}-05$ & 0 & 0 & 0 & $4.44 \mathrm{E}-06$ & $1.64 \mathrm{E}-05$ \\
\hline
\end{tabular}




\begin{tabular}{|c|c|c|c|c|c|c|}
\hline HGF & 0.000150798 & 0.000108605 & 0 & 0 & 0 & 0 \\
\hline IGFBP-1 & $1.72 \mathrm{E}-05$ & $1.19 \mathrm{E}-06$ & 0 & 0.002371223 & 0.002948347 & 0.000794802 \\
\hline IGFBP-2 & 0.03838013 & $2.36 \mathrm{E}-05$ & 0.019261407 & 0.000800783 & 0.000553975 & 0.000167784 \\
\hline IGFBP-3 & 0.00020026 & 0.001165699 & 0.000171262 & 0.005406744 & 0.001752351 & 0.001958266 \\
\hline IGFBP-4 & 0.031543588 & 0 & 0.024088804 & 0.03510373 & 0.027153016 & 0.009237969 \\
\hline IGFBP-6 & $2.10 \mathrm{E}-05$ & 0 & 0 & 0.000390494 & 0.000119614 & 0.000110561 \\
\hline IGF-1 & 0 & 0 & 0 & 0 & 0 & 0 \\
\hline Insulin & 0.001044058 & 0.000180137 & 0.000168729 & $1.93 \mathrm{E}-05$ & $3.44 \mathrm{E}-07$ & 0 \\
\hline MCSF R & 0 & 0 & 0 & 0 & $2.64 \mathrm{E}-06$ & 0 \\
\hline NGF R & 0 & 0 & 0 & $2.58 \mathrm{E}-05$ & $1.61 \mathrm{E}-05$ & $1.46 \mathrm{E}-05$ \\
\hline NT-3 & $4.90 \mathrm{E}-05$ & 0 & 0 & 0 & 0 & $1.96 \mathrm{E}-05$ \\
\hline NT-4 & 0 & 0 & $1.82 \mathrm{E}-05$ & 4.92E-05 & $2.59 \mathrm{E}-05$ & $2.82 \mathrm{E}-05$ \\
\hline OPG & 0.000686742 & $5.60 \mathrm{E}-06$ & 0.000191447 & 0.000123978 & $2.06 \mathrm{E}-05$ & $4.00 \mathrm{E}-05$ \\
\hline PDGF-AA & 0.001285513 & 0 & 0.000706263 & 4.44E-05 & $6.61 \mathrm{E}-05$ & $2.31 \mathrm{E}-05$ \\
\hline PIGF & $3.38 \mathrm{E}-06$ & 0 & $2.33 \mathrm{E}-06$ & $1.68 \mathrm{E}-05$ & $2.67 \mathrm{E}-05$ & $8.24 \mathrm{E}-06$ \\
\hline SCF & 0.000268546 & $1.21 \mathrm{E}-05$ & $5.52 \mathrm{E}-05$ & 4.27E-05 & $2.64 \mathrm{E}-05$ & $2.18 \mathrm{E}-05$ \\
\hline SCF R & $2.66 \mathrm{E}-05$ & $1.81 \mathrm{E}-06$ & $5.52 \mathrm{E}-07$ & $1.83 \mathrm{E}-05$ & 0 & 0 \\
\hline TGFa & $2.43 \mathrm{E}-06$ & $6.21 \mathrm{E}-08$ & $4.01 \mathrm{E}-07$ & $1.57 \mathrm{E}-06$ & $3.81 \mathrm{E}-06$ & $2.33 \mathrm{E}-06$ \\
\hline TGFb1 & 0.007929901 & 0 & 0.004063648 & 0.017025033 & 0.019838083 & 0.014877531 \\
\hline TGFb3 & 0.000190967 & 4.30E-05 & $1.10 \mathrm{E}-05$ & 0 & 0 & $1.04 \mathrm{E}-05$ \\
\hline VEGF & 0.000875898 & $5.85 \mathrm{E}-06$ & 0.001037997 & 0.000664594 & 0.001612044 & 0.000417328 \\
\hline VEGF R2 & 0 & $2.18 \mathrm{E}-06$ & 0 & 0.00028497 & 0.000185174 & 0.000288385 \\
\hline VEGF R3 & $6.34 \mathrm{E}-07$ & 0 & 0 & 0 & $1.46 \mathrm{E}-05$ & 0 \\
\hline VEGF-D & 0 & 0 & 0 & $9.98 \mathrm{E}-06$ & 0 & 0 \\
\hline $\mathrm{BLC}$ & 0 & 6.03E-08 & $1.18 \mathrm{E}-06$ & $1.46 \mathrm{E}-06$ & $1.19 \mathrm{E}-06$ & $3.35 \mathrm{E}-06$ \\
\hline Eotaxin & $2.50 \mathrm{E}-06$ & 0 & $3.83 \mathrm{E}-07$ & 0 & $2.48 \mathrm{E}-06$ & $7.86 \mathrm{E}-07$ \\
\hline Eotaxin-2 & 0 & 0 & 0 & 4.84E-06 & $1.33 \mathrm{E}-05$ & $9.82 \mathrm{E}-06$ \\
\hline G-CSF & $9.11 \mathrm{E}-07$ & $1.90 \mathrm{E}-07$ & 0 & 0.000203949 & 0.000538688 & 7.17E-05 \\
\hline GM-CSF & 0 & 0 & 0 & $3.40 \mathrm{E}-05$ & $3.23 \mathrm{E}-05$ & $2.45 \mathrm{E}-05$ \\
\hline I-309 & 0 & 0 & 0 & $1.15 \mathrm{E}-06$ & $5.27 \mathrm{E}-06$ & 2.33E-06 \\
\hline ICAM-1 & 0.002948357 & 0.000480536 & 0.001032933 & 0.016178641 & 0.011874304 & 0.010645761 \\
\hline IFNg & 0 & 0 & $2.05 \mathrm{E}-06$ & 4.87E-06 & $3.03 \mathrm{E}-06$ & $5.64 \mathrm{E}-06$ \\
\hline IL-1a & $1.03 \mathrm{E}-05$ & 0 & 0 & $4.68 \mathrm{E}-05$ & $6.82 \mathrm{E}-05$ & $8.17 \mathrm{E}-05$ \\
\hline IL-1b & $8.54 \mathrm{E}-07$ & 0 & 0 & $1.63 \mathrm{E}-05$ & $7.96 \mathrm{E}-06$ & $1.25 \mathrm{E}-05$ \\
\hline IL-1 ra & $1.42 \mathrm{E}-06$ & 0 & 0 & $4.29 \mathrm{E}-06$ & $3.79 \mathrm{E}-06$ & $2.78 \mathrm{E}-06$ \\
\hline IL-2 & $1.76 \mathrm{E}-07$ & $2.56 \mathrm{E}-06$ & 4.27E-06 & 2.09E-05 & $1.37 \mathrm{E}-05$ & $3.49 \mathrm{E}-05$ \\
\hline
\end{tabular}




\begin{tabular}{|c|c|c|c|c|c|c|}
\hline IL-4 & 0 & 0 & 0 & $2.76 \mathrm{E}-05$ & $3.84 \mathrm{E}-06$ & $3.06 \mathrm{E}-05$ \\
\hline IL-5 & $1.27 \mathrm{E}-05$ & 6.03E-06 & 7.33E-06 & 4.37E-06 & $1.40 \mathrm{E}-05$ & $8.66 \mathrm{E}-06$ \\
\hline IL-6 & 0 & $2.71 \mathrm{E}-05$ & 4.87E-05 & 0.005839015 & 0.005347526 & 0.001303217 \\
\hline IL-6R & 0.00047905 & $3.10 \mathrm{E}-05$ & 0.000442797 & 0.00010098 & 0.000134065 & 0.0001382 \\
\hline IL-7 & 0.000101402 & $8.55 \mathrm{E}-05$ & $8.72 \mathrm{E}-05$ & $3.45 \mathrm{E}-06$ & $4.52 \mathrm{E}-06$ & $3.82 \mathrm{E}-06$ \\
\hline IL-8 & $7.20 \mathrm{E}-06$ & $1.27 \mathrm{E}-06$ & $6.21 \mathrm{E}-06$ & 0.000625293 & 0.000354265 & 0.000300696 \\
\hline IL-10 & $1.38 \mathrm{E}-06$ & $1.75 \mathrm{E}-06$ & $2.05 \mathrm{E}-06$ & $1.22 \mathrm{E}-06$ & $1.23 \mathrm{E}-06$ & $1.77 \mathrm{E}-06$ \\
\hline IL-11 & 8.90E-06 & $2.73 \mathrm{E}-05$ & $5.31 \mathrm{E}-05$ & 0.000100496 & $8.58 \mathrm{E}-05$ & $3.02 \mathrm{E}-05$ \\
\hline IL-12p40 & 0 & 0 & 0 & $2.96 \mathrm{E}-07$ & $1.18 \mathrm{E}-06$ & $9.83 \mathrm{E}-07$ \\
\hline IL-12p70 & 0 & 4.46E-07 & $5.52 \mathrm{E}-07$ & $1.77 \mathrm{E}-07$ & $3.01 \mathrm{E}-07$ & $2.65 \mathrm{E}-07$ \\
\hline IL-13 & 0 & 0 & 8.19E-05 & $1.24 \mathrm{E}-06$ & 2.39E-06 & $1.59 \mathrm{E}-06$ \\
\hline IL-15 & 0 & 0 & 0 & 4.41E-06 & $6.28 \mathrm{E}-06$ & $6.41 \mathrm{E}-06$ \\
\hline IL-16 & 8.32E-06 & 0 & $2.97 \mathrm{E}-06$ & $2.66 \mathrm{E}-06$ & $4.51 \mathrm{E}-06$ & $4.36 \mathrm{E}-06$ \\
\hline IL-17 & 0 & 0 & 0 & $2.66 \mathrm{E}-05$ & $1.73 \mathrm{E}-05$ & $1.50 \mathrm{E}-05$ \\
\hline MCP-1 & $2.26 \mathrm{E}-05$ & $1.94 \mathrm{E}-06$ & $3.01 \mathrm{E}-06$ & 0.000613812 & 0.000413376 & 0.000241177 \\
\hline MCSF & 4.35E-06 & $1.08 \mathrm{E}-06$ & $5.69 \mathrm{E}-07$ & 0.000619423 & 0.000484264 & 0.000234508 \\
\hline MIG & 0 & 0 & 0 & 4.78E-05 & $2.84 \mathrm{E}-05$ & $3.78 \mathrm{E}-05$ \\
\hline MIP-1a & $5.76 \mathrm{E}-06$ & $1.77 \mathrm{E}-07$ & $5.62 \mathrm{E}-07$ & 4.18E-06 & $3.06 \mathrm{E}-06$ & $2.87 \mathrm{E}-06$ \\
\hline MIP-1b & 0 & 0 & 3.97E-08 & 0.000484075 & 0.000333782 & 0.00011085 \\
\hline MIP-1d & $2.60 \mathrm{E}-05$ & $6.32 \mathrm{E}-07$ & $6.72 \mathrm{E}-05$ & 0 & $3.75 \mathrm{E}-07$ & $1.80 \mathrm{E}-07$ \\
\hline PDGF-BB & 0.000260116 & 0 & 0.00011116 & $1.12 \mathrm{E}-05$ & $1.63 \mathrm{E}-06$ & $7.25 \mathrm{E}-07$ \\
\hline RANTES & $1.82 \mathrm{E}-05$ & 0 & $1.04 \mathrm{E}-05$ & 0.002044813 & 0.001384339 & 0.001016627 \\
\hline TIMP-1 & 0.026128371 & 0.000155777 & 0.016099051 & 0.007553942 & 0.006278853 & 0.003834425 \\
\hline TIMP-2 & 0.006191568 & $4.80 \mathrm{E}-06$ & 0.007047748 & 0.030479665 & 0.013735155 & 0.008755265 \\
\hline $\mathrm{TNFa}$ & 0 & 0 & 0 & $2.21 \mathrm{E}-05$ & $6.68 \mathrm{E}-06$ & $1.01 \mathrm{E}-05$ \\
\hline $\mathrm{TNFb}$ & 0 & $3.05 \mathrm{E}-06$ & $2.84 \mathrm{E}-05$ & $4.40 \mathrm{E}-05$ & $5.89 \mathrm{E}-05$ & 8.79E-05 \\
\hline TNF RI & 0.005626251 & $6.53 \mathrm{E}-05$ & 0.001616636 & 0.001322491 & 0.001408391 & 0.000573725 \\
\hline TNF RII & 6.99E-05 & $3.05 \mathrm{E}-05$ & $1.83 \mathrm{E}-05$ & $5.47 \mathrm{E}-05$ & 4.36E-05 & $2.66 \mathrm{E}-05$ \\
\hline 4-1BB & 0 & 0 & 0 & $1.62 \mathrm{E}-05$ & $2.62 \mathrm{E}-05$ & $1.44 \mathrm{E}-05$ \\
\hline ALCAM & 0.000449516 & 0 & 0.000202712 & 0.002490335 & 0.001480593 & 0.00068372 \\
\hline B7-1 & 0 & 0 & 0 & $1.81 \mathrm{E}-05$ & $3.44 \mathrm{E}-05$ & $6.17 \mathrm{E}-08$ \\
\hline BCMA & 0 & 0 & 0 & 0 & 0 & 0 \\
\hline CD14 & 0 & 0 & 0 & 3.99E-05 & $2.43 \mathrm{E}-05$ & $2.36 \mathrm{E}-05$ \\
\hline CD30 & 0 & 0 & 0 & $1.23 \mathrm{E}-05$ & 0.000180145 & 7.95E-05 \\
\hline CD40L & 0 & $1.50 \mathrm{E}-05$ & 0 & 0.000193611 & $6.46 \mathrm{E}-05$ & 0.000119416 \\
\hline CEACAM-1 & 0 & 0 & 0 & 0.000410175 & 0.000287367 & $9.20 \mathrm{E}-05$ \\
\hline
\end{tabular}




\begin{tabular}{|c|c|c|c|c|c|c|}
\hline DR6 & $6.54 \mathrm{E}-05$ & 0 & $6.26 \mathrm{E}-05$ & 0.003603996 & 0.004034371 & 0.000896132 \\
\hline Dtk & 0 & 0 & 0 & 0 & 5.34E-05 & 4.23E-05 \\
\hline Endoglin & 0 & 0 & 0 & 0 & $1.66 \mathrm{E}-05$ & $4.28 \mathrm{E}-06$ \\
\hline ErbB3 & 0.000719941 & $4.05 \mathrm{E}-06$ & 0.000128655 & 7.63E-05 & $3.56 \mathrm{E}-05$ & 4.87E-05 \\
\hline E-Selectin & 0 & 0 & 0 & 0.006274286 & 0.004531215 & 0.001681711 \\
\hline Fas & 0 & 0 & 0 & 0 & 0 & $1.06 \mathrm{E}-05$ \\
\hline Flt-3L & $3.00 \mathrm{E}-06$ & $3.07 \mathrm{E}-07$ & $1.62 \mathrm{E}-06$ & $3.59 \mathrm{E}-06$ & 3.79E-06 & 0 \\
\hline GITR & 0 & 0 & 0 & 0 & 0 & $7.75 \mathrm{E}-06$ \\
\hline HVEM & 0 & 0 & 0 & 0 & 0 & $2.02 \mathrm{E}-05$ \\
\hline ICAM-3 & $6.44 \mathrm{E}-07$ & 0 & 0 & 0 & $2.23 \mathrm{E}-05$ & $8.15 \mathrm{E}-05$ \\
\hline Contactin-2 & 0 & 0 & 0 & $3.53 \mathrm{E}-06$ & 0 & $5.57 \mathrm{E}-05$ \\
\hline IL-1 RI & 0 & $9.61 \mathrm{E}-07$ & $1.95 \mathrm{E}-06$ & $3.27 \mathrm{E}-06$ & 4.19E-06 & $5.45 \mathrm{E}-06$ \\
\hline IL-2 Rg & 0 & $5.86 \mathrm{E}-05$ & 0 & 0 & $2.38 \mathrm{E}-06$ & 0 \\
\hline IL-10 Rb & 0 & 0 & 0 & $1.14 \mathrm{E}-05$ & 0 & 0 \\
\hline IL-17R & 0 & 0 & 0 & 0.000432926 & 0.000163145 & 0.000161675 \\
\hline IL-21R & 0 & 0 & 0 & 0.000407122 & 0.00034796 & 0 \\
\hline LIMPII & $9.96 \mathrm{E}-07$ & 0 & 0 & 0.002455471 & 0.001315258 & 0.001404589 \\
\hline Lipocalin-2 & $1.33 \mathrm{E}-05$ & 0 & $2.16 \mathrm{E}-05$ & 0.001219403 & 0.001088732 & 0.000863765 \\
\hline L-Selectin & 0 & 0 & 0 & 0 & 0 & 0 \\
\hline LYVE-1 & 0 & 0 & 0 & $2.36 \mathrm{E}-05$ & $9.96 \mathrm{E}-06$ & $1.17 \mathrm{E}-05$ \\
\hline MICA & 0 & 0 & 0 & 0.000274176 & 0.000265747 & 0 \\
\hline MICB & $5.15 \mathrm{E}-05$ & 0 & $9.76 \mathrm{E}-06$ & 0.000165091 & 0.000691765 & $9.39 \mathrm{E}-05$ \\
\hline NRG1-b1 & $1.14 \mathrm{E}-05$ & $4.21 \mathrm{E}-06$ & 0 & 0 & $4.89 \mathrm{E}-05$ & 0 \\
\hline PDGF Rb & 0 & 0 & 0 & 0 & 0.000187274 & 0 \\
\hline PECAM-1 & $1.64 \mathrm{E}-05$ & 0 & $1.73 \mathrm{E}-05$ & 0 & 0 & 0 \\
\hline RAGE & 0 & $5.42 \mathrm{E}-07$ & 0 & $1.23 \mathrm{E}-05$ & $1.09 \mathrm{E}-05$ & $6.18 \mathrm{E}-06$ \\
\hline TIM-1 & 0 & 0 & 0 & $1.16 \mathrm{E}-05$ & 7.43E-06 & $8.50 \mathrm{E}-06$ \\
\hline TRAIL R3 & 0 & 0 & 0 & $9.23 \mathrm{E}-06$ & 0 & $1.64 \mathrm{E}-05$ \\
\hline Trappin-2 & $9.31 \mathrm{E}-05$ & 0 & 0.000127158 & 0.001886039 & 0.001595932 & 0.000306887 \\
\hline uPAR & 0.000212093 & 0 & 0.0003666683 & 0.003164916 & 0.00323144 & 0.001284836 \\
\hline VCAM-1 & 0 & 0 & 7.87E-06 & 0 & 0 & 0 \\
\hline XEDAR & 0 & 0 & 0 & $3.30 \mathrm{E}-05$ & $3.32 \mathrm{E}-05$ & 0 \\
\hline
\end{tabular}

